NASA/CR—2018-219907

\title{
Space Qualified 200-Watt Q-band Linearized Traveling-Wave Tube Amplifier
}

Neal Robbins, David Eze, Helen Cohen, Xiaoling Zhai, William McGeary, and William Menninger L3 Technologies, Inc., Electron Devices Division, Torrance, California

Morgan Chen and Eddie Rodgers

L3 Technologies, Inc., Narda Microwave West, Folsom, California 


\section{NASA STI Program . . . in Profile}

Since its founding, NASA has been dedicated to the advancement of aeronautics and space science. The NASA Scientific and Technical Information (STI) Program plays a key part in helping NASA maintain this important role.

The NASA STI Program operates under the auspices of the Agency Chief Information Officer. It collects, organizes, provides for archiving, and disseminates NASA's STI. The NASA STI Program provides access to the NASA Technical Report Server-Registered (NTRS Reg) and NASA Technical Report ServerPublic (NTRS) thus providing one of the largest collections of aeronautical and space science STI in the world. Results are published in both non-NASA channels and by NASA in the NASA STI Report Series, which includes the following report types:

- TECHNICAL PUBLICATION. Reports of completed research or a major significant phase of research that present the results of NASA programs and include extensive data or theoretical analysis. Includes compilations of significant scientific and technical data and information deemed to be of continuing reference value. NASA counter-part of peer-reviewed formal professional papers, but has less stringent limitations on manuscript length and extent of graphic presentations.

- TECHNICAL MEMORANDUM. Scientific and technical findings that are preliminary or of specialized interest, e.g., "quick-release" reports, working papers, and bibliographies that contain minimal annotation. Does not contain extensive analysis.
- CONTRACTOR REPORT. Scientific and technical findings by NASA-sponsored contractors and grantees.

- CONFERENCE PUBLICATION. Collected papers from scientific and technical conferences, symposia, seminars, or other meetings sponsored or co-sponsored by NASA.

- SPECIAL PUBLICATION. Scientific, technical, or historical information from NASA programs, projects, and missions, often concerned with subjects having substantial public interest.

- TECHNICAL TRANSLATION. Englishlanguage translations of foreign scientific and technical material pertinent to NASA's mission.

For more information about the NASA STI program, see the following:

- Access the NASA STI program home page at http://www.sti.nasa.gov

- E-mail your question to help@sti.nasa.gov

- $\quad$ Fax your question to the NASA STI Information Desk at 757-864-6500

- Telephone the NASA STI Information Desk at 757-864-9658

- Write to:

NASA STI Program

Mail Stop 148

NASA Langley Research Center Hampton, VA 23681-2199 
NASA/CR—2018-219907

\section{Space Qualified 200-Watt Q-band Linearized Traveling-Wave Tube Amplifier}

Neal Robbins, David Eze, Helen Cohen, Xiaoling Zhai, William McGeary, and William Menninger L3 Technologies, Inc., Electron Devices Division, Torrance, California

Morgan Chen and Eddie Rodgers

L3 Technologies, Inc., Narda Microwave West, Folsom, California

Prepared under Contract NNC12CA45C

National Aeronautics and

Space Administration

Glenn Research Center

Cleveland, Ohio 44135 


\section{Acknowledgments}

Initial funding for the 9922H Q-band TWT design was provided under NASA Glenn Research Center contract no. NNC12CA45C. Dr. Rainee N. Simons served as the contracting officer technical representative (COTR).

This report contains preliminary findings, subject to revision as analysis proceeds.

Level of Review: This material has been technically reviewed by NASA expert reviewer(s).

Available from

NASA STI Program

Mail Stop 148

NASA Langley Research Center

Hampton, VA 23681-2199
National Technical Information Service 5285 Port Royal Road Springfield, VA 22161 703-605-6000

This report is available in electronic form at http://www.sti.nasa.gov/ and http://ntrs.nasa.gov/ 


\title{
Space Qualified 200-Watt Q-band Linearized Traveling-Wave Tube Amplifier
}

\author{
L3 Technologies, Inc. \\ Electron Devices Division \\ Torrance, California 90505 \\ Morgan Chen and Eddie Rodgers \\ L3 Technologies, Inc. \\ Narda Microwave West \\ Folsom, California 95630
}

Neal Robbins, David Eze, Helen Cohen, Xiaoling Zhai, William McGeary, and William Menninger

\begin{abstract}
L3 Technologies Electron Devices Division, (L3 EDD) and L3 Technologies Narda Microwave West (L3 NMW), are completing space-flight qualification for a 200 -watt Q-band linearized channelized traveling-wave tube amplifier (LCTWTA) capable of over $5 \mathrm{GHz}$ instantaneous bandwidth in a conduction-cooled package. This report will discuss the LCTWTA performance, manufacturing and flight qualification test results.
\end{abstract}

\section{Introduction}

The model $2600 \mathrm{H}$ linearized, channel-amplifier traveling-wave tube amplifier (LCTWTA), designed and fabricated by L3 Technologies Electron Devices Division (L3 EDD) and Narda Microwave West (L3 NMW), consists of a linearized channel amplifier (LCAMP), traveling-wave tube (TWT), and electronic power conditioner (EPC), which have all completed or nearly completed flight qualification testing. Producing up to $200 \mathrm{~W}$ of $\mathrm{CW}$ saturated RF power over bandwidths over up to $5.0 \mathrm{GHz}$ in the 37.5 -to- $42.5 \mathrm{GHz}$ $\mathrm{Q}$ frequency band; this LCTWTA represents the highest CW power helix TWT qualified for space applications at Q-band. It maintains typical efficiency, linearity and noise performance. In addition, a linearized, channel amplifier for the same band is completing qualification at L3 Technologies Narda Microwave West (L3 NMW). Together, the 9922H TWT and the linearized channel amplifier, combined with an L3 EDD electronic power conditioner such as the $2600 \mathrm{H}$, will provide unprecedented amplifier performance for commercial space downlink applications.

\section{Background}

This report discusses the L3 EDD Q-band LCTWTA. It produces up to $200 \mathrm{~W}$ of $\mathrm{CW}$, linearized saturated RF power over up to $5 \mathrm{GHz}$ in the $\mathrm{Q}$ frequency band. Figure 1 shows the model $2600 \mathrm{H}$ EPC with the model $9922 \mathrm{H}$ conduction-cooled TWT next to the L3 NMW linearizer and channel amplifier (LCAMP).

\section{Traveling-Wave Tube (TWT)}

The TWT model 9922H employs a helical RF circuit with periodic, permanent magnet (PPM) focusing packaged for conduction cooling. The electron gun is a dual-anode, isolatedfocus-electrode design, and is designed for greater than 15 years of mission life. The helix circuit is designed to provide CW saturated RF output power up to $200 \mathrm{~W}$ RF over the 37.5 to $42.5 \mathrm{GHz}$ Q-band frequency range. The $9922 \mathrm{H}$ was designed primarily using the Naval Research Laboratory codes CHRISTINE 3D (Ref. 1) and MICHELLE (Ref. 2).

\section{TWT Qualification}

The model $9922 \mathrm{H}$ TWT is completing flight qualification. Measured RF performance at ambient temperature is shown in Table I.

The TWT body current at saturated drive level is below $0.6 \mathrm{~mA}$ while the output power exceeds $200 \mathrm{~W}$ across 37.5 to $42.5 \mathrm{GHz}$ with an average efficiency of 60 percent. The following additional test results are presented in the Appendix:

- RF output Power vs. time at a fixed frequency of $40 \mathrm{GHz}$

- Input and output return loss vs. frequency

- Single tone RF output power vs. input drive from saturation at several frequencies

- Saturated output power vs. frequency

- Small signal gain and phase vs. frequency

- Collector currents and body current vs. input power relative to saturation

- Total DC power, RF output power, and thermal dissipation vs. input power relative to saturation

The overall space-flight qualification effort includes a range of operating and nonoperating environmental tests. TWT qualification testing began after exhaustive acceptance test processing and performance quantification. Qualification testing includes random vibration testing, pyrotechnic shock testing, and thermal-vacuum cycling. The random vibration is at levels of up to $18.9 \mathrm{Grms}$ for a minimum of $3 \mathrm{~min}$ per axis. For shock testing a high-performance vibration table was used to simulate a shock 


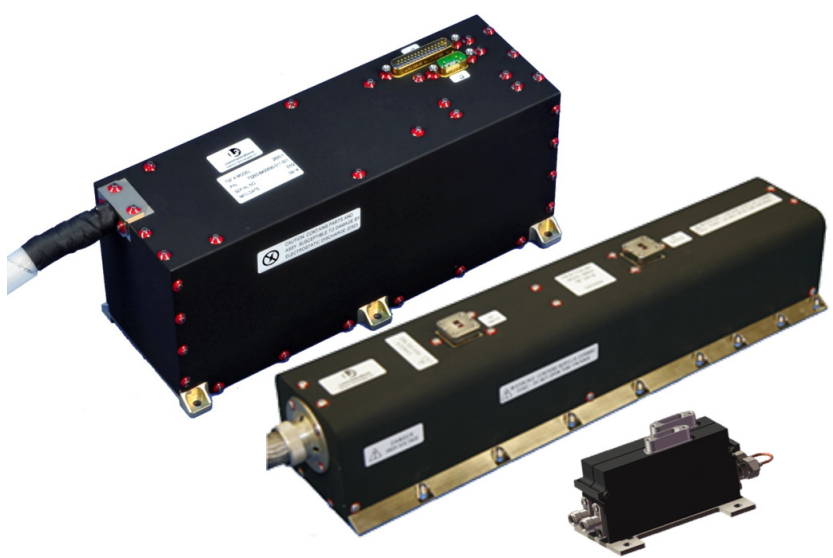

Figure 1.-2600H EPC (upper left) with 9922H TWT (middle) and L3 NMW LCAMP (lower right).

TABLE I._-9922H TWT PERFORMANCE

\begin{tabular}{|c|c|c|c|c|}
\hline $\begin{array}{c}\text { Frequency, } \\
\text { GHz }\end{array}$ & 37.5 & 40.0 & 42.5 & (No drive) \\
\hline Drive level & \multicolumn{3}{|c|}{ Saturated } & \\
\hline Iw, mA & 0.42 & 0.44 & 0.55 & 0.13 \\
\hline Pin, $\mathrm{dBm}$ & 0.3 & -1.2 & -0.3 & ----- \\
\hline Saturated Pout, W & 204 & 208 & 201 & ----- \\
\hline Saturated Gain, dB & 52.8 & 54.4 & 53.4 & $\begin{array}{ll}---- \\
\end{array}$ \\
\hline Total DC, W & 335 & 347 & 346 & 112 \\
\hline Thermal Dissipation, W & 131 & 139 & 145 & 112 \\
\hline Overall Efficency, \% & 61.0 & 59.9 & 58.2 & $\begin{array}{ll}---- \\
\end{array}$ \\
\hline
\end{tabular}

pulse over the frequency range from $100 \mathrm{~Hz}$ to $10 \mathrm{KHz}$. Each test was performed three times per axis for a total of 9 pyrotechnic shock qualification pulses at levels of up to $2590 \mathrm{~g}$ 's. Thermal vacuum testing is now being performed over all operating conditions from nonoperating to full RF power. Sixteen (16) thermal vacuum cycles will be performed over the temperature range of -20 to $86{ }^{\circ} \mathrm{C}$. Four "cold starts" will soak the nonoperating TWT to thermal stability at $-35{ }^{\circ} \mathrm{C}$ and then initiating a full RF power start and $\mathrm{CW}$ operation. The unit will also demonstrate nonoperating survival from -35 to $95{ }^{\circ} \mathrm{C}$. Additional details on the sinusoidal vibration, random vibration, shock, thermal vacuum cycles, environmental qualification performance, and life test experience are presented in the Appendix.

At each intermediate step and again once all environmental testing completed, the TWT will be exercised through a full functional and operational test regime.

\section{Electronic Power Conditioner (EPC)}

The electronic power conditioner (EPC) shown in Figure 1 is model $2600 \mathrm{H}$, qualified in 2016 (Ref. 3). This EPC is capable of processing up to $600 \mathrm{~W}$ of DC power at voltages of up to $12 \mathrm{kV}$. The EPC can be configured to accept either regulated or unregulated spacecraft bus voltages of up to $100 \mathrm{~V}$. The EPC efficiency ranges between 91 and 95 percent depending on the spacecraft bus voltage interface and environmental extremes requirements. At power levels below approximately $40 \mathrm{~W}$, the Q-band TWT can mate to the lighter L3 EDD model $2000 \mathrm{H}$ or $2410 \mathrm{H}$ EPCs which provide cathode voltages up to $7 \mathrm{kV}$.

\section{Linearized Channel Amplifier (LCAMP)}

The L3 NMW LCAMP is shown at the lower right in Figure 1. An LCAMP consists of a channel amplifier (CAMP) and linearizer. The CAMP operates in fixed gain mode (FGM) or automatic-level-control (ALC) mode. In ALC mode, a fixed drive level is provided to the linearizer over a wide input dynamic range. In the fixed gain mode (FGM), the CAMP provides a variable gain that may be used for various system purposes such as ground mode testing. The CAMP provides $53 \mathrm{~dB}$ linear gain across the 37.5 to $42.5 \mathrm{GHz}$ band. The linearizer is a unity-gain pre-distorter that follows the CAMP. Its purpose is to compensate TWT nonlinearity and provide reduced back-off levels of operation to enhance system linearity, power, and efficiency. Figure 2 shows typical improvement in noise power ratio (NPR) achieved by the linearizer. The LCAMP thermally compensates for the TWTA performance with thermistor-based control circuitry. Both CAMP and linearizer are mounted to a common baseplate and take an $8 \mathrm{~V}$ supply with $7 \mathrm{~W}$ power consumption. RF input and output connectors are coaxial $2.4 \mathrm{~mm}$.

The LCTWTA has an input dynamic range from -49 to $-13 \mathrm{dBm}$ with 36 gain steps in $1.0 \pm 0.3 \mathrm{~dB}$ increments in FGM. In ALC mode, this LCTWTA has a minimum control range of +2 to $-13 \mathrm{~dB}$ relative to saturation with 30 gain steps in $0.5 \pm 0.25 \mathrm{~dB}$ increments, and typically $18 \mathrm{~dB}$ range with 36 control increments. The linearizer provides $\sim 5 \mathrm{~dB}$ gain expansion and $40^{\circ}$ phase expansion over swept power with $20^{\circ}$ intentional phase expansion variation across frequency to match TWTA characteristics.

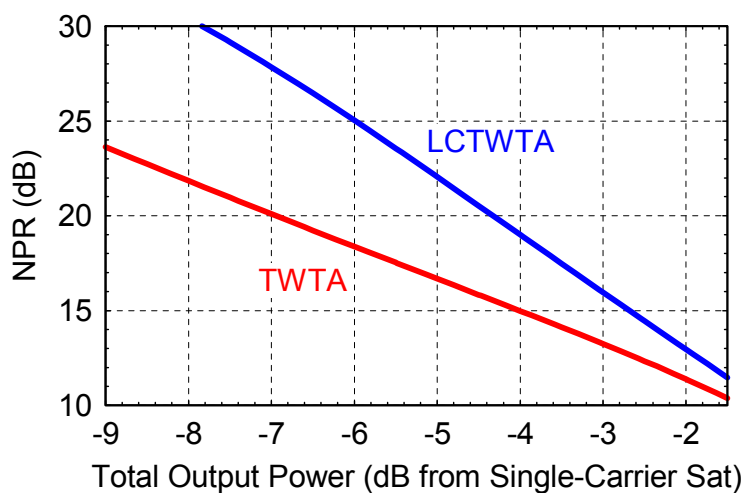

Figure 2.-Simulated LCTWTA NPR performance based on measured EM TWT and LCAMP data. 


\section{Conclusion}

As a result of the thorough qualification testing, L3 EDD, with support from L3 NMW, is prepared to offer unprecedented Q-band RF amplifier performance from a flight-qualificationtested LCTWTA delivering power levels up to $200 \mathrm{~W}$ with LCTWTA efficiencies over 50 percent and NPR approaching $20 \mathrm{~dB}$ at $4.5 \mathrm{~dB}$ OBO from saturation.

\section{References}

1. T.M. Antonsen, D.P. Chernin, S.J. Cooke and B. Levush, "Spurious reflection of space charge fields in TWTAs," in IEEE Transactions on Electron Devices, vol. 52, no. 5, pp. 755-763, May 2005.
2. J.J. Petillo, E.M. Nelson, J.F. DeFord, N.J. Dionne and B. Levush, "Recent developments to the MICHELLE 2-D/3-D electron gun and collector modeling code," in IEEE Transactions on Electron Devices, vol. 52, no. 5, pp. 742-748, May 2005.

3. N.R. Robbins, W.L. Menninger, X. Zhai and D.E. Lewis, "Space qualified, 150-300-watt K-band TWTA," 2016 IEEE International Vacuum Electronics Conference (IVEC), Monterey, CA, 2016, pp. 1-2. 



\section{Appendix-Additional RF Test Results and Details on Environmental Qualification}





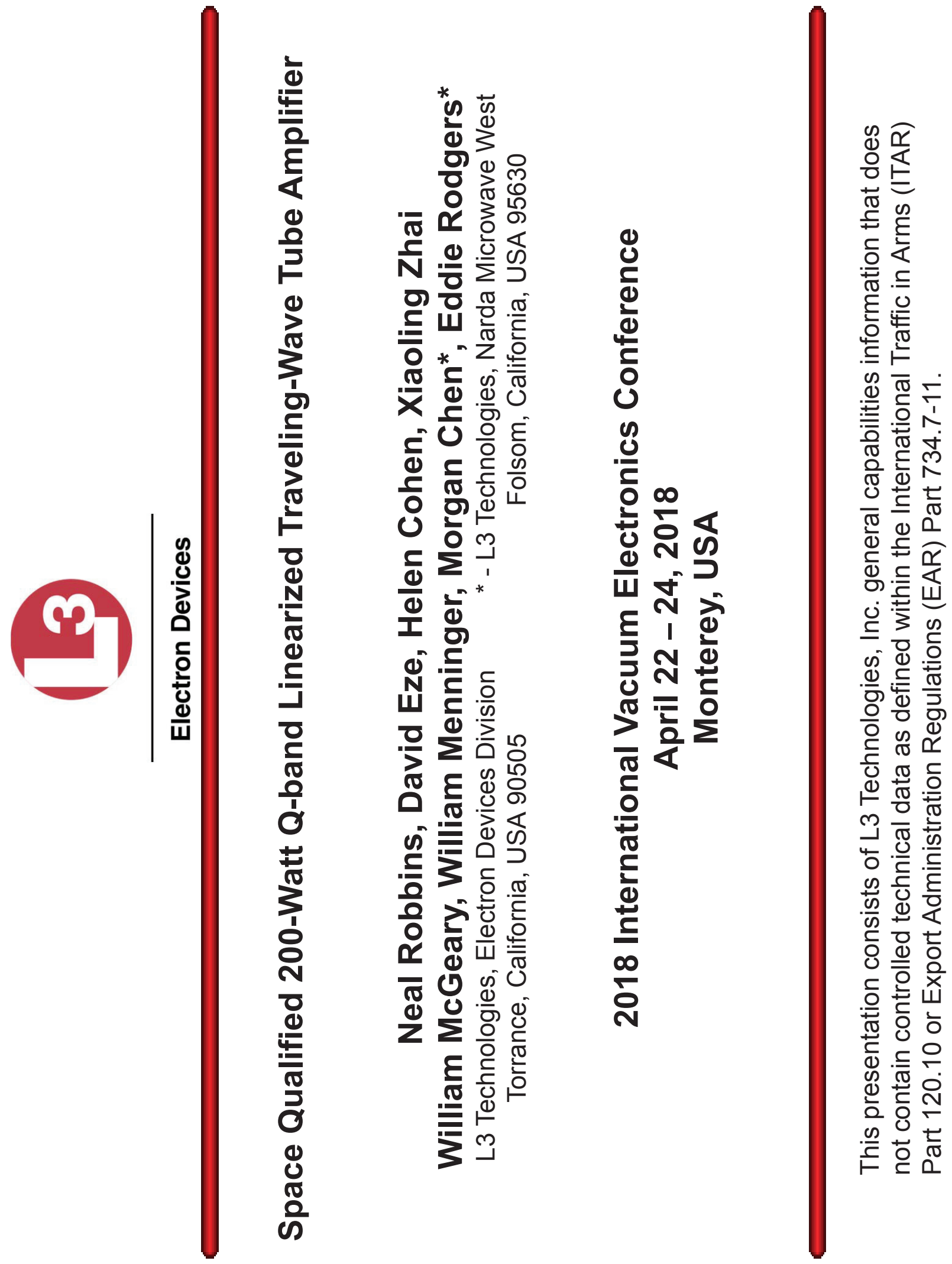



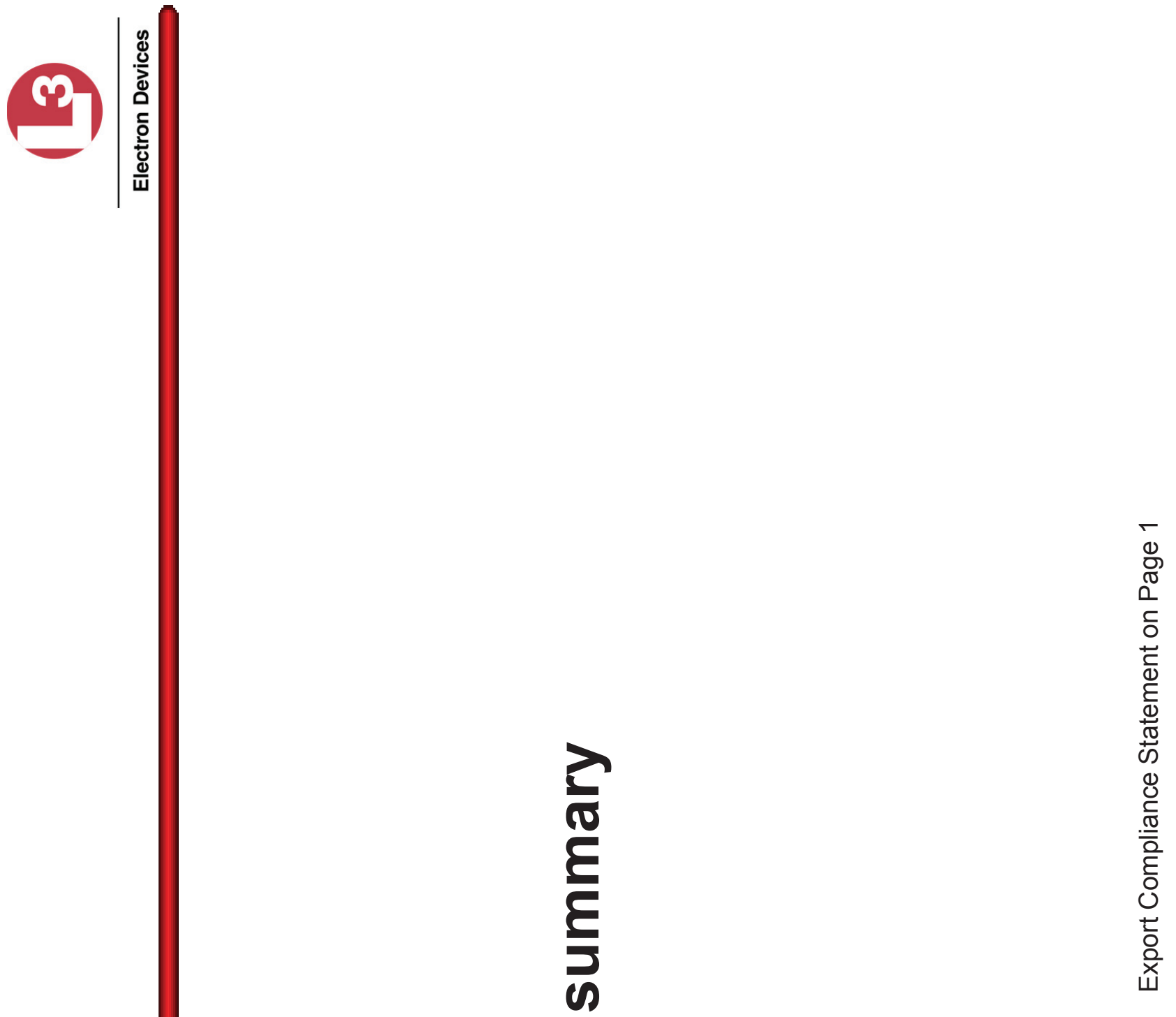


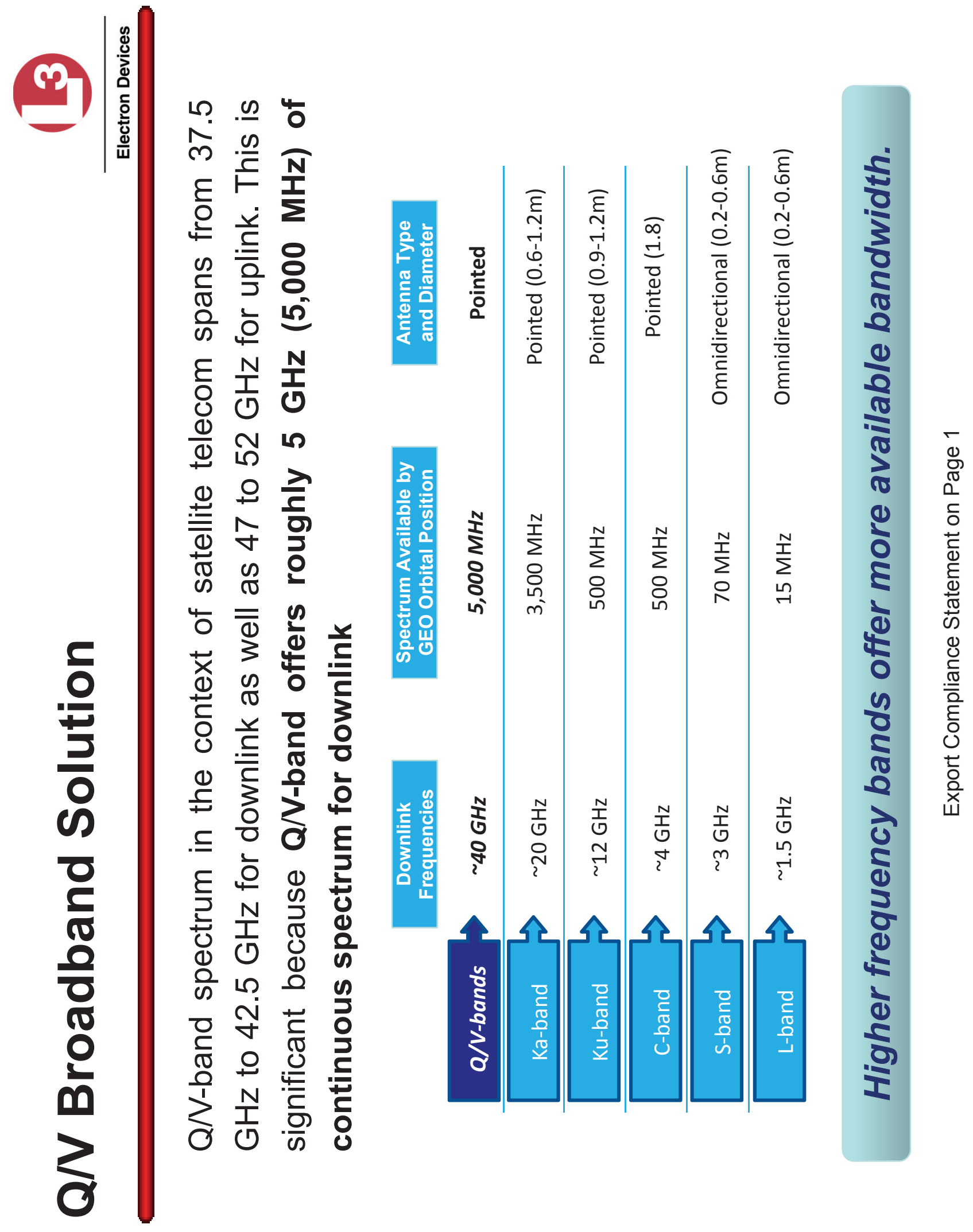




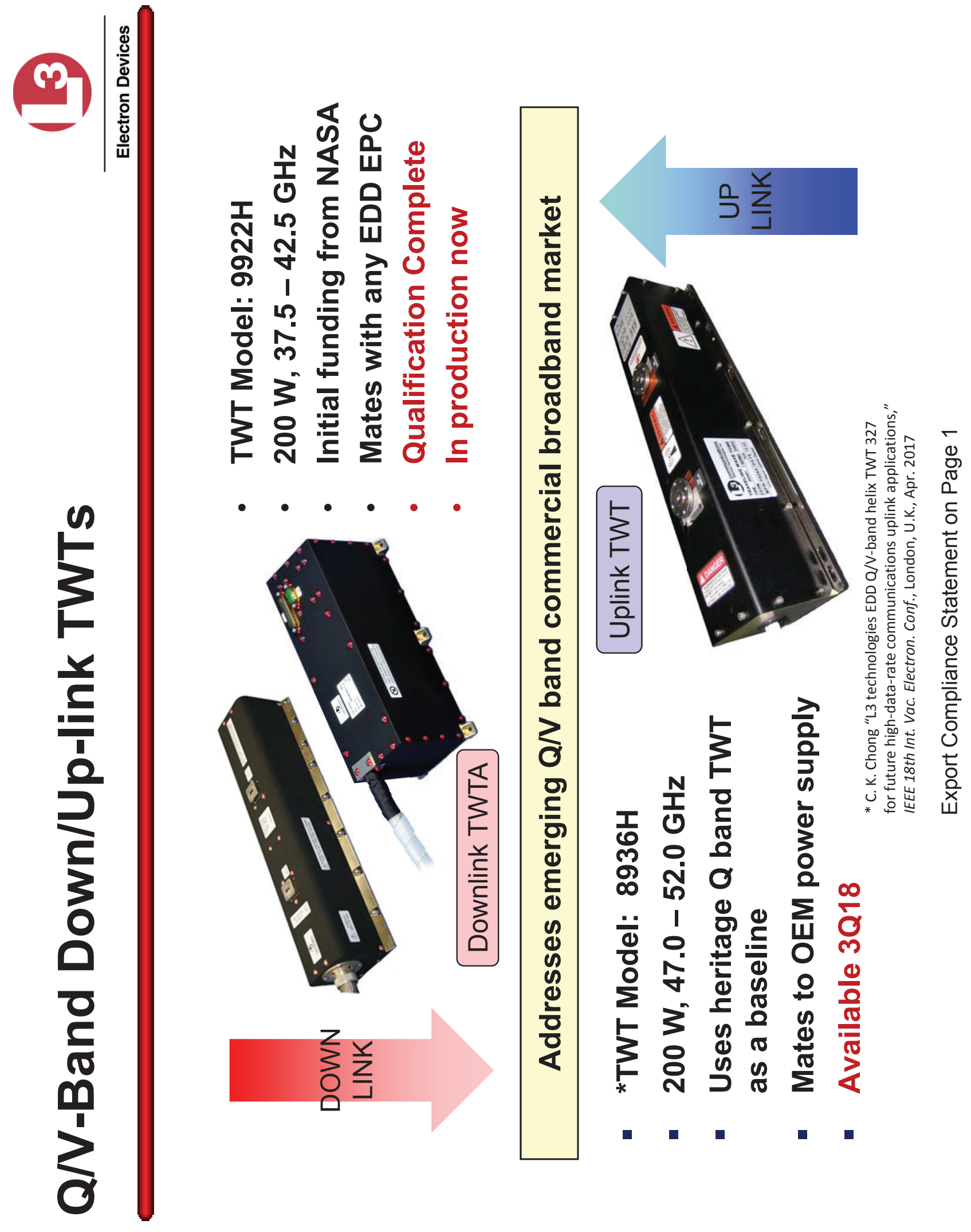




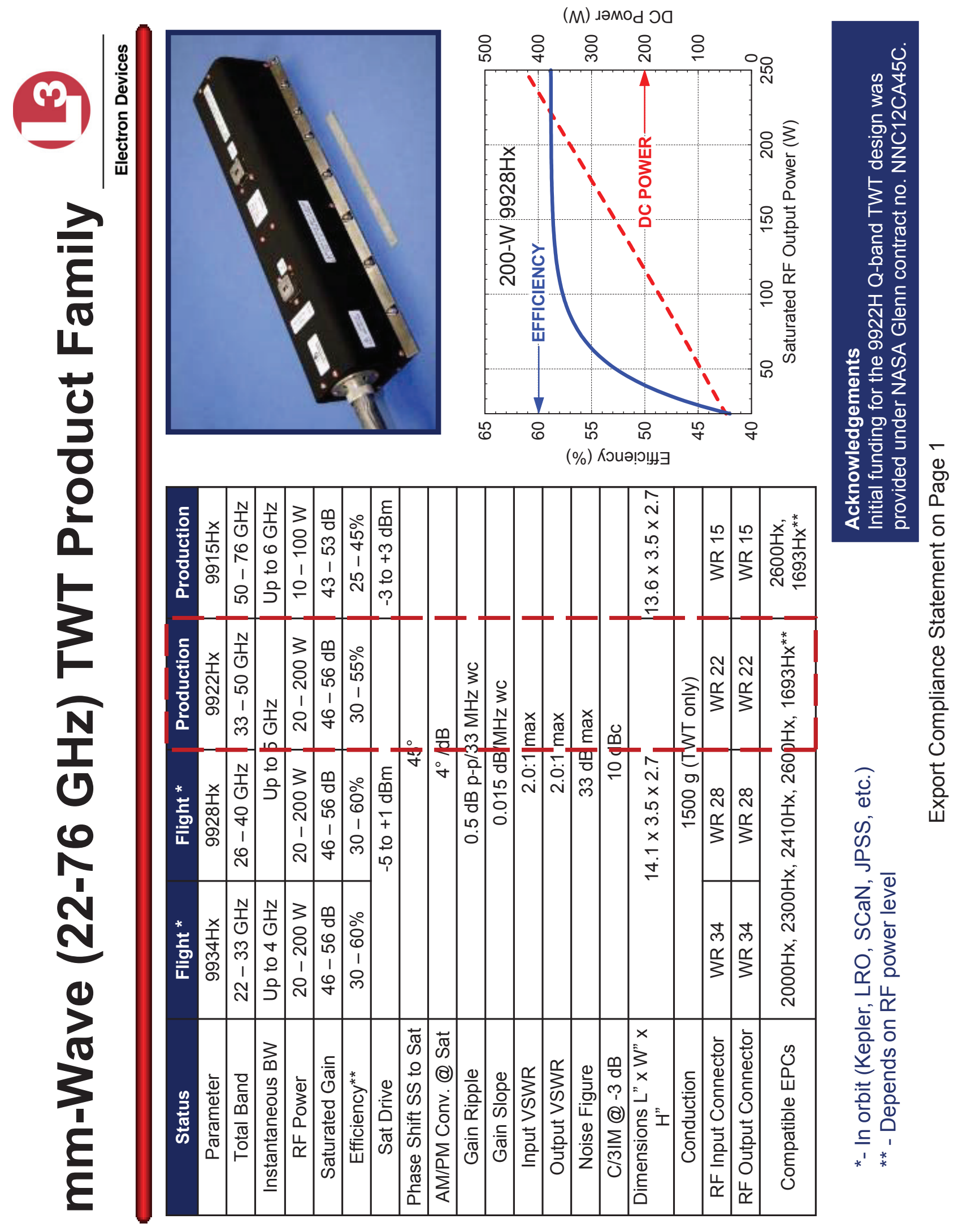




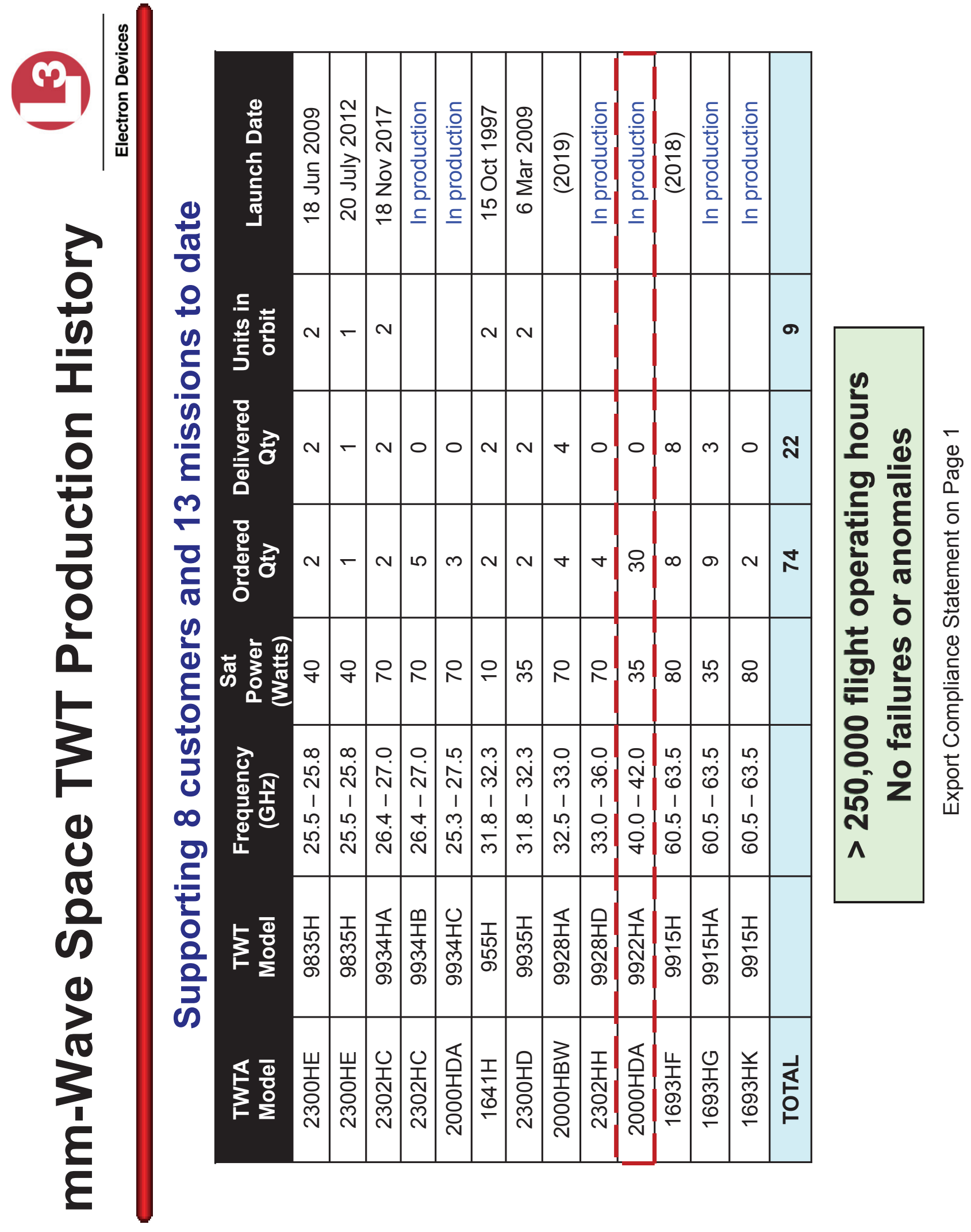




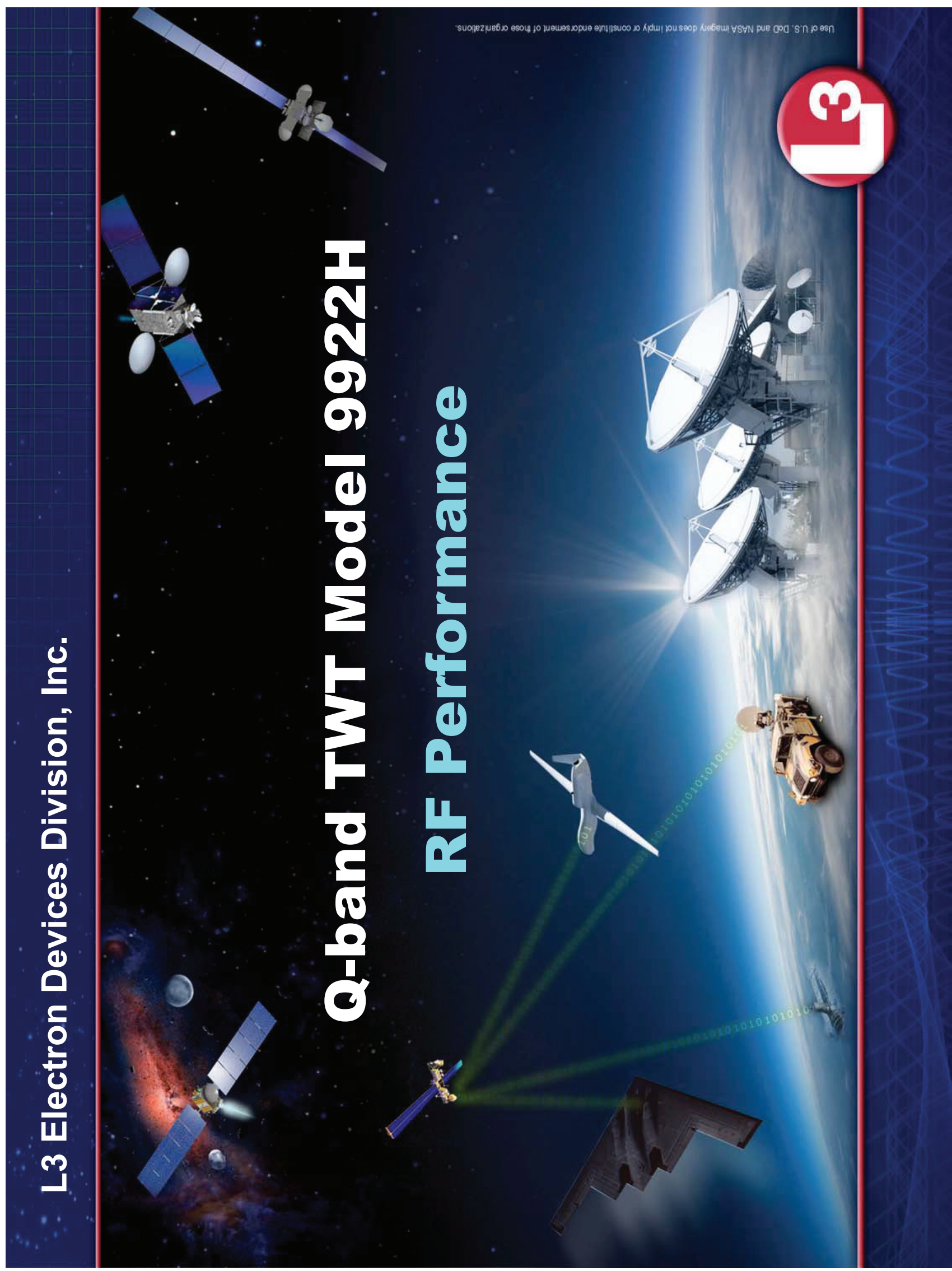

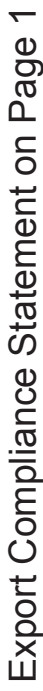




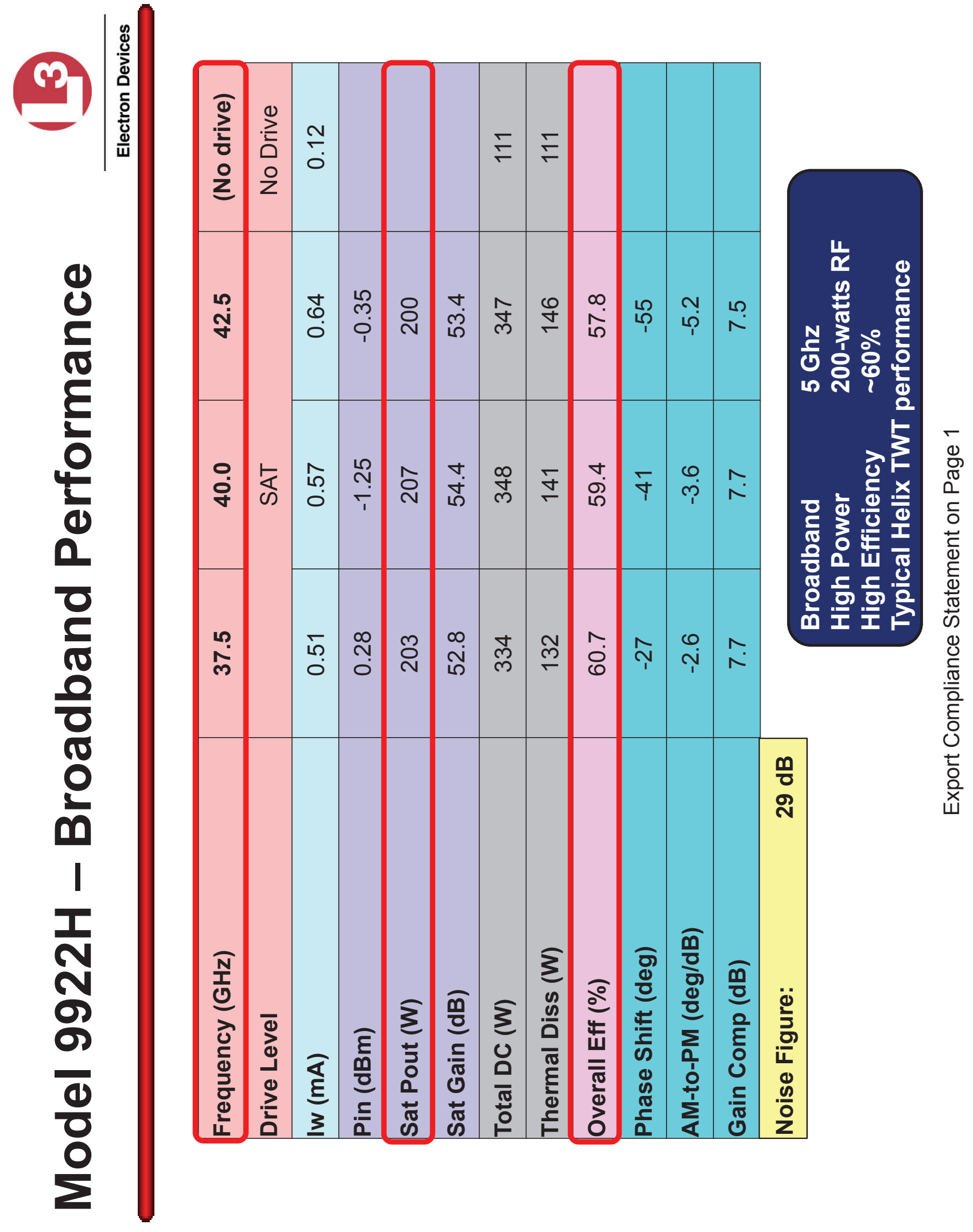




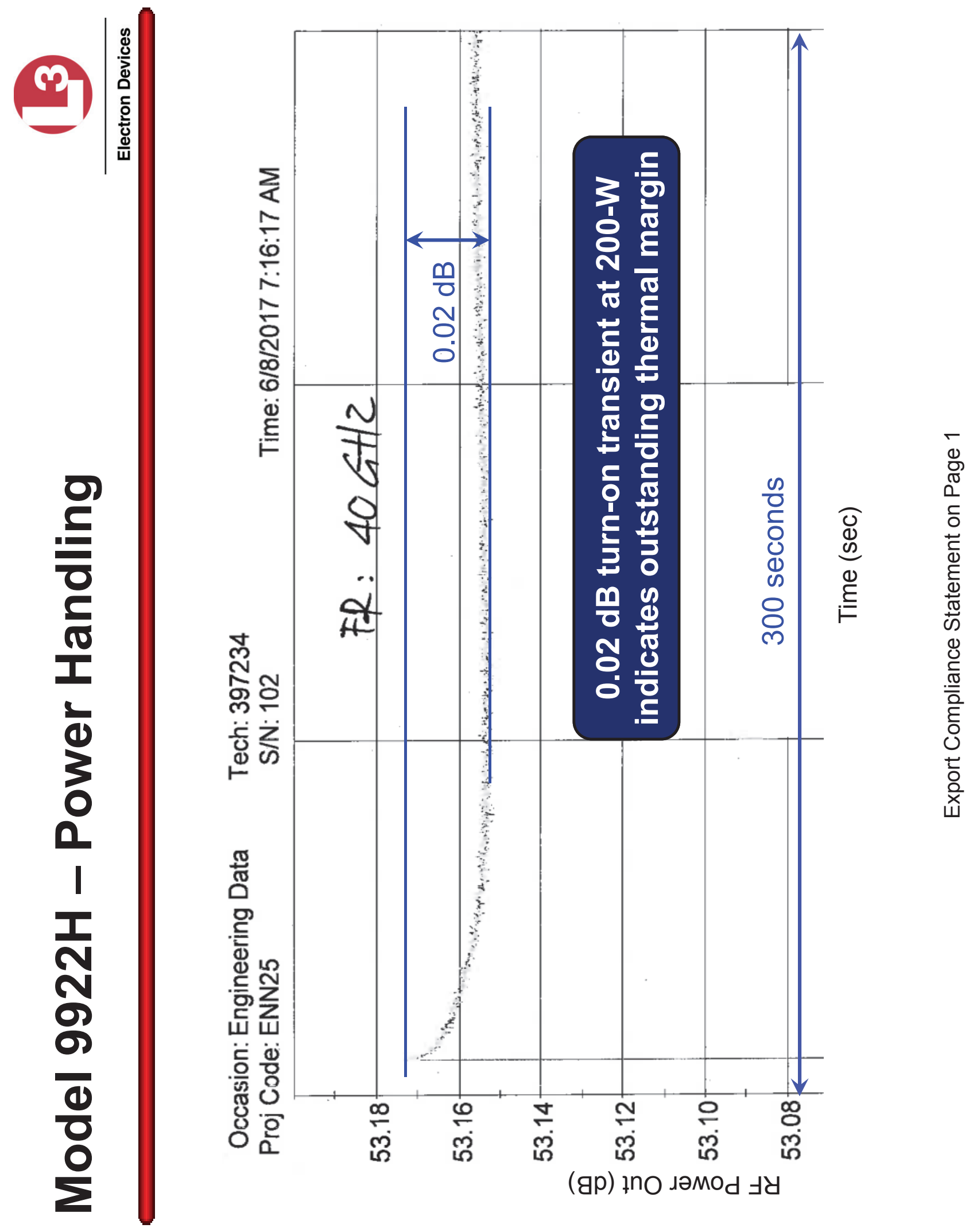




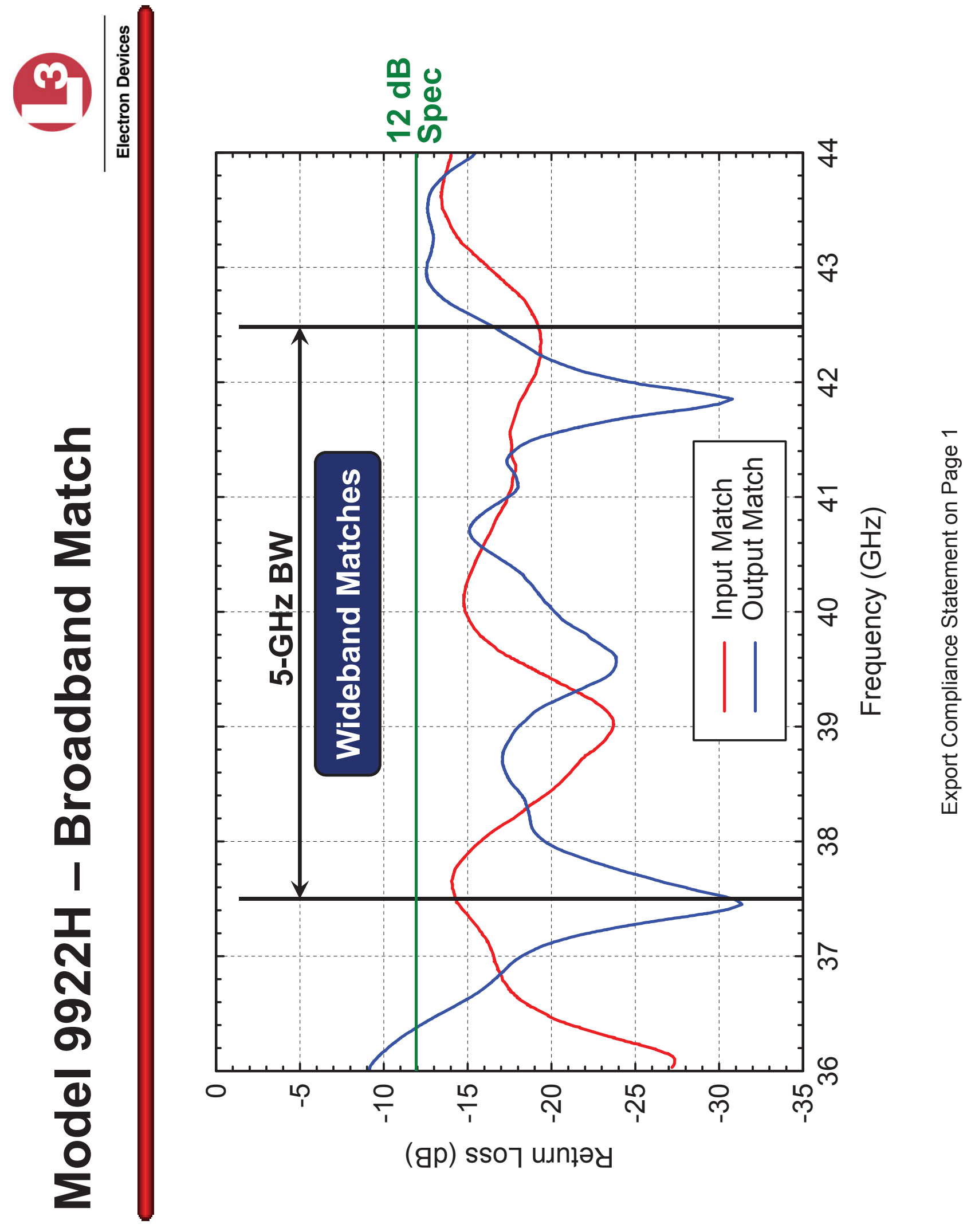




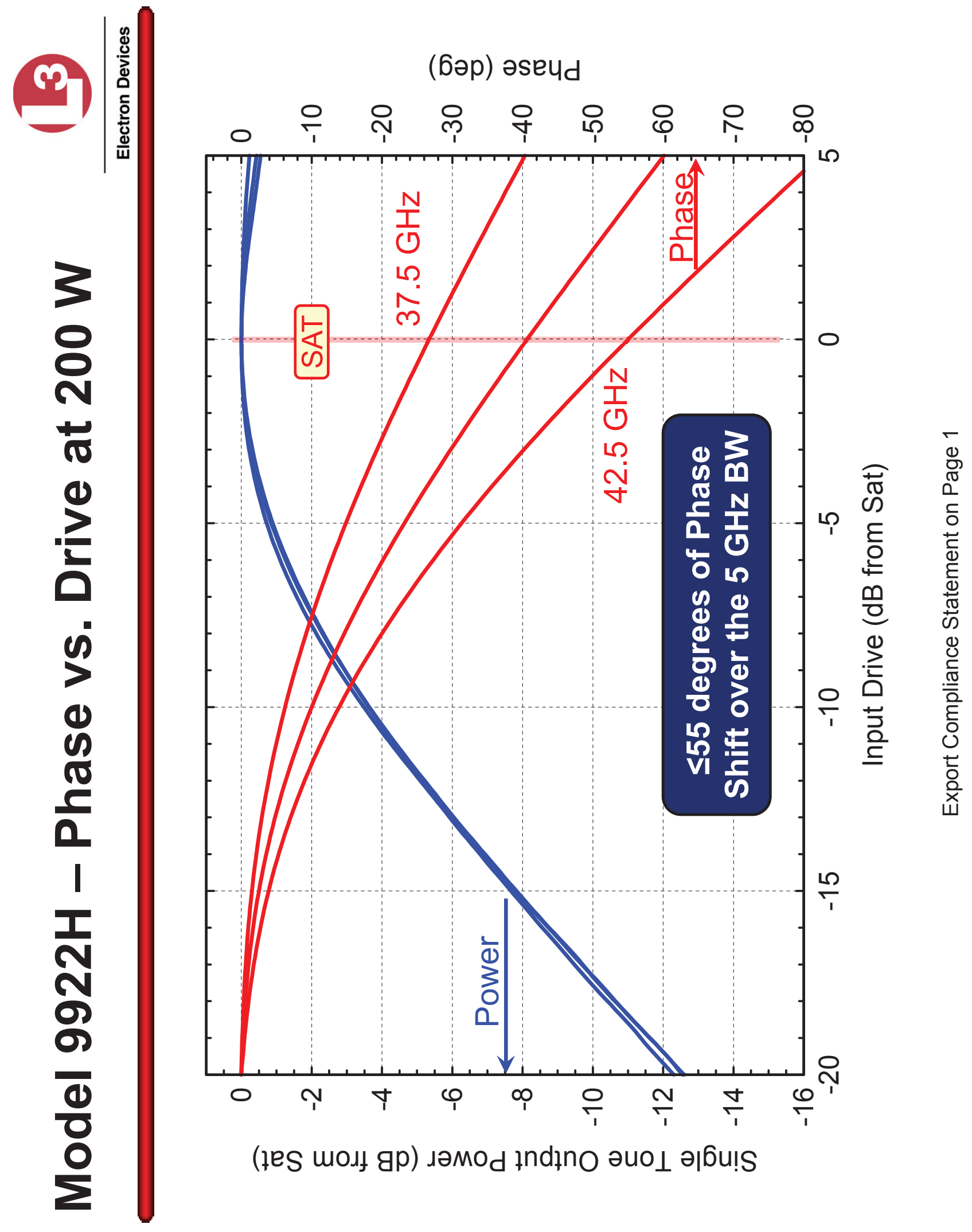




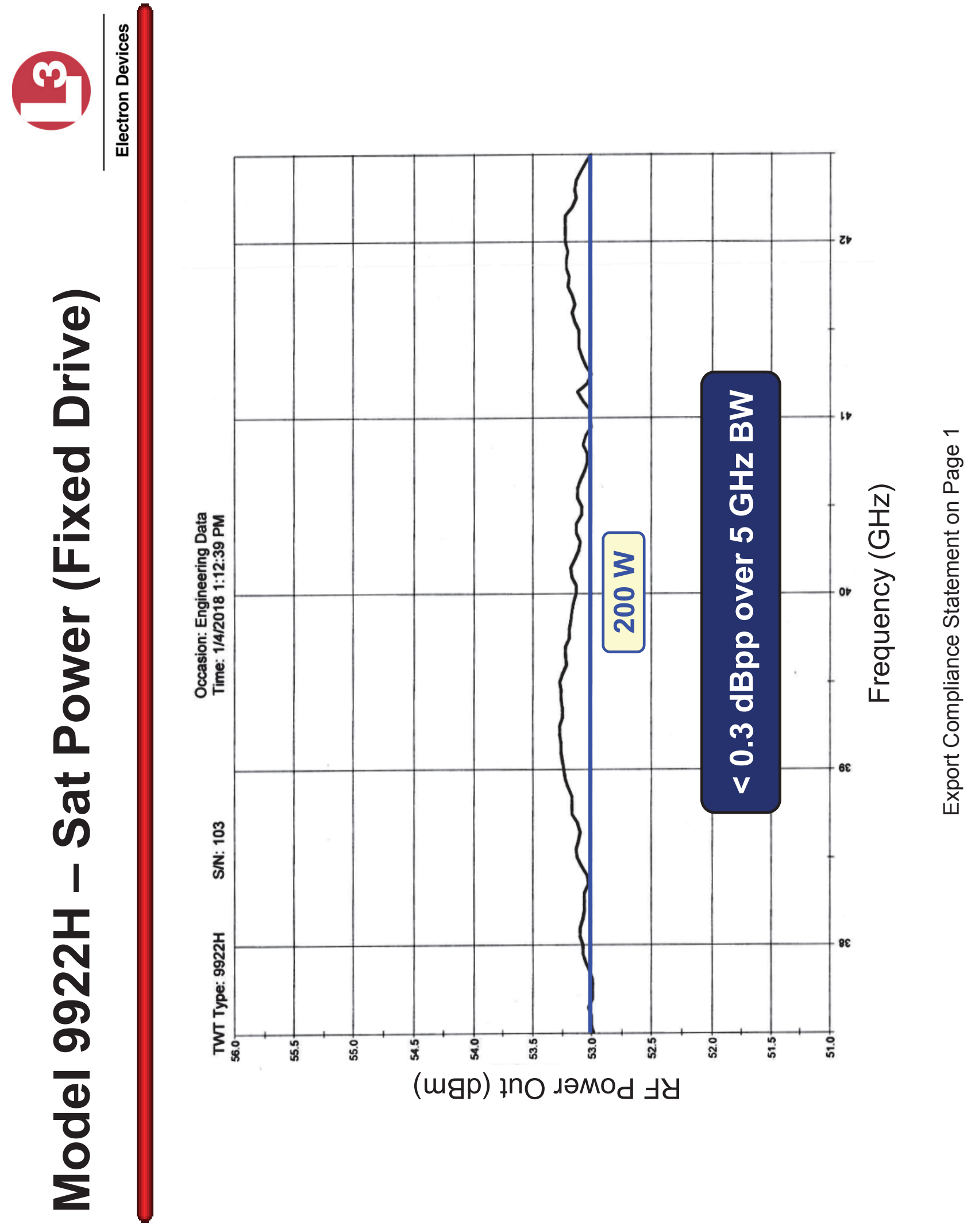









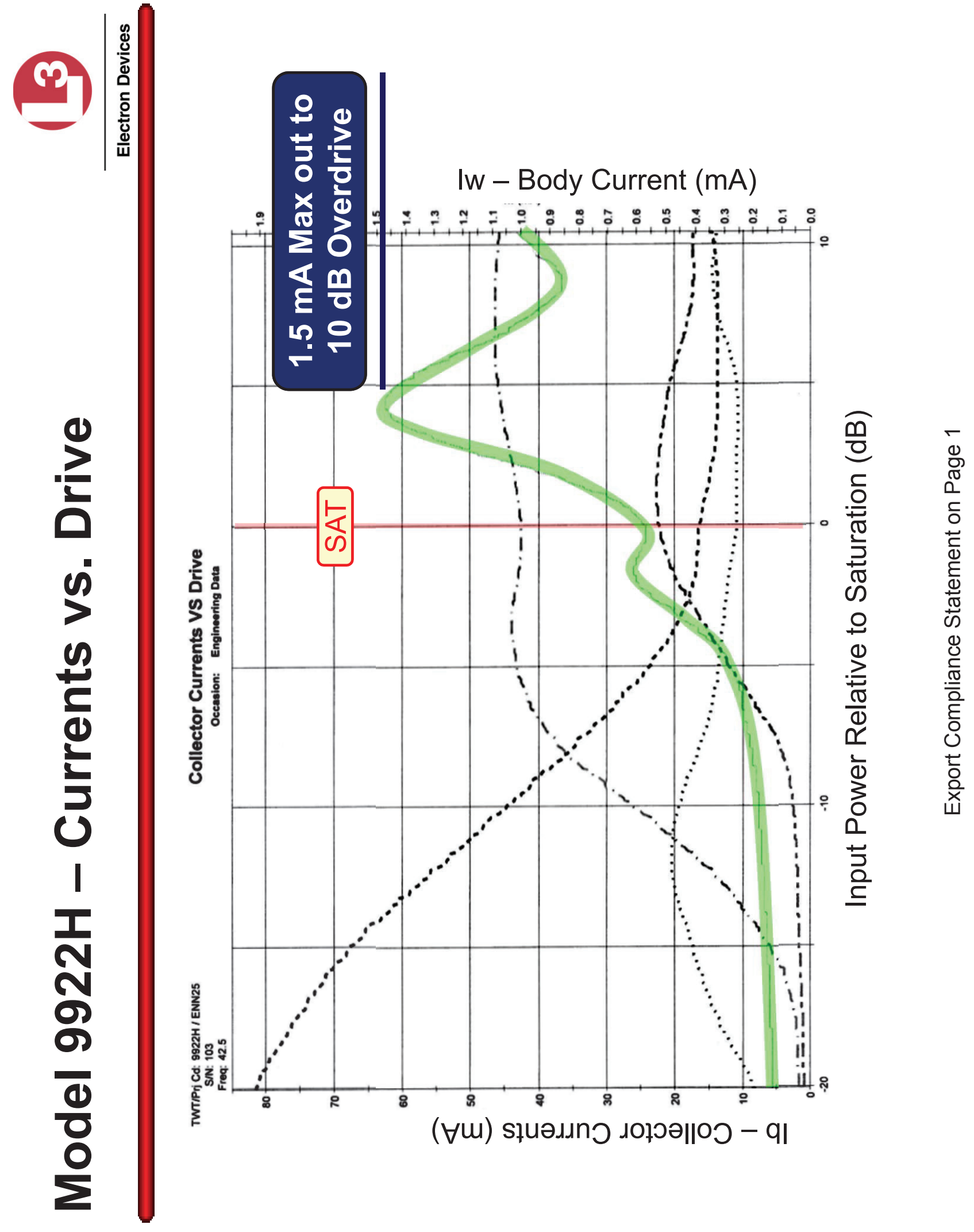




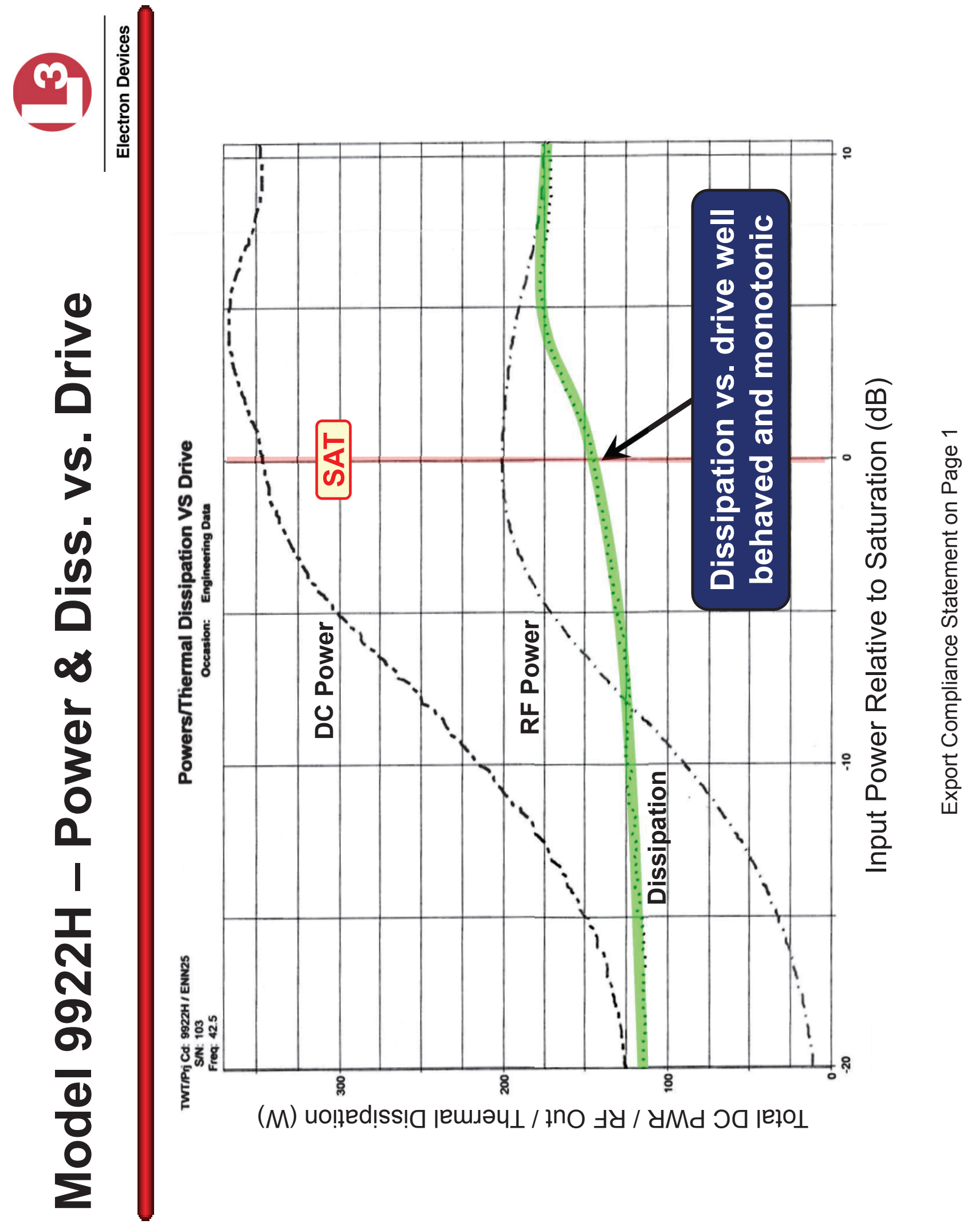




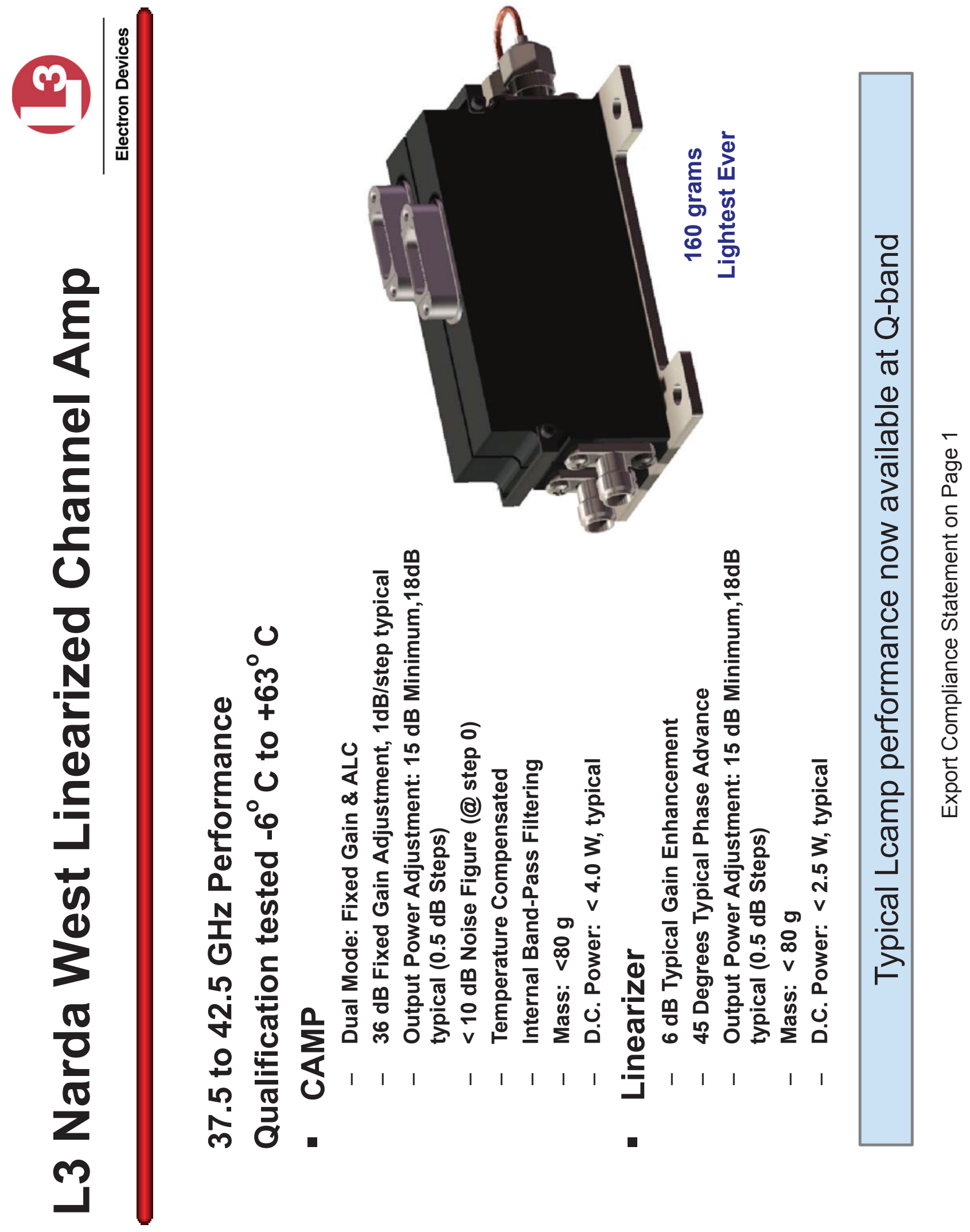




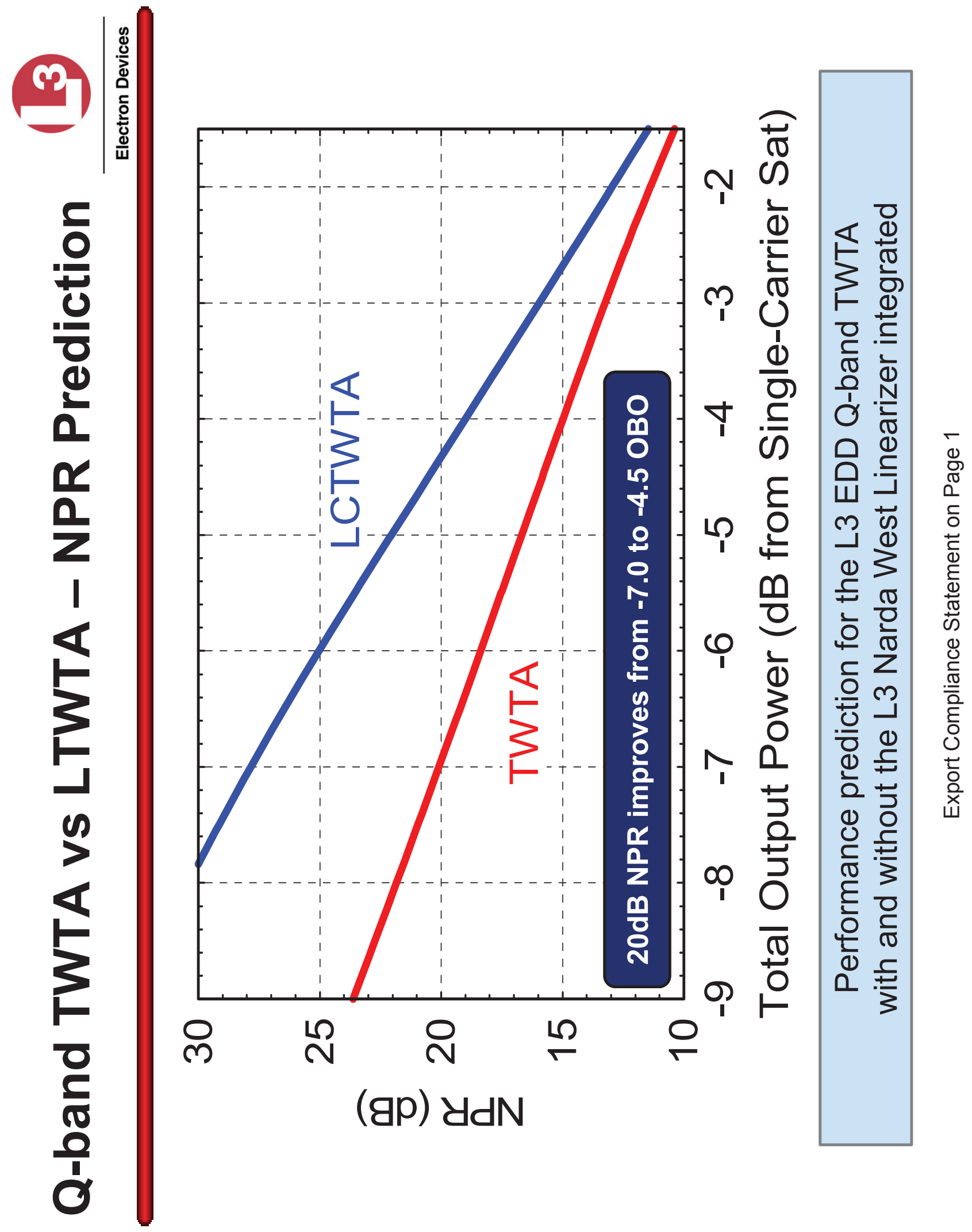




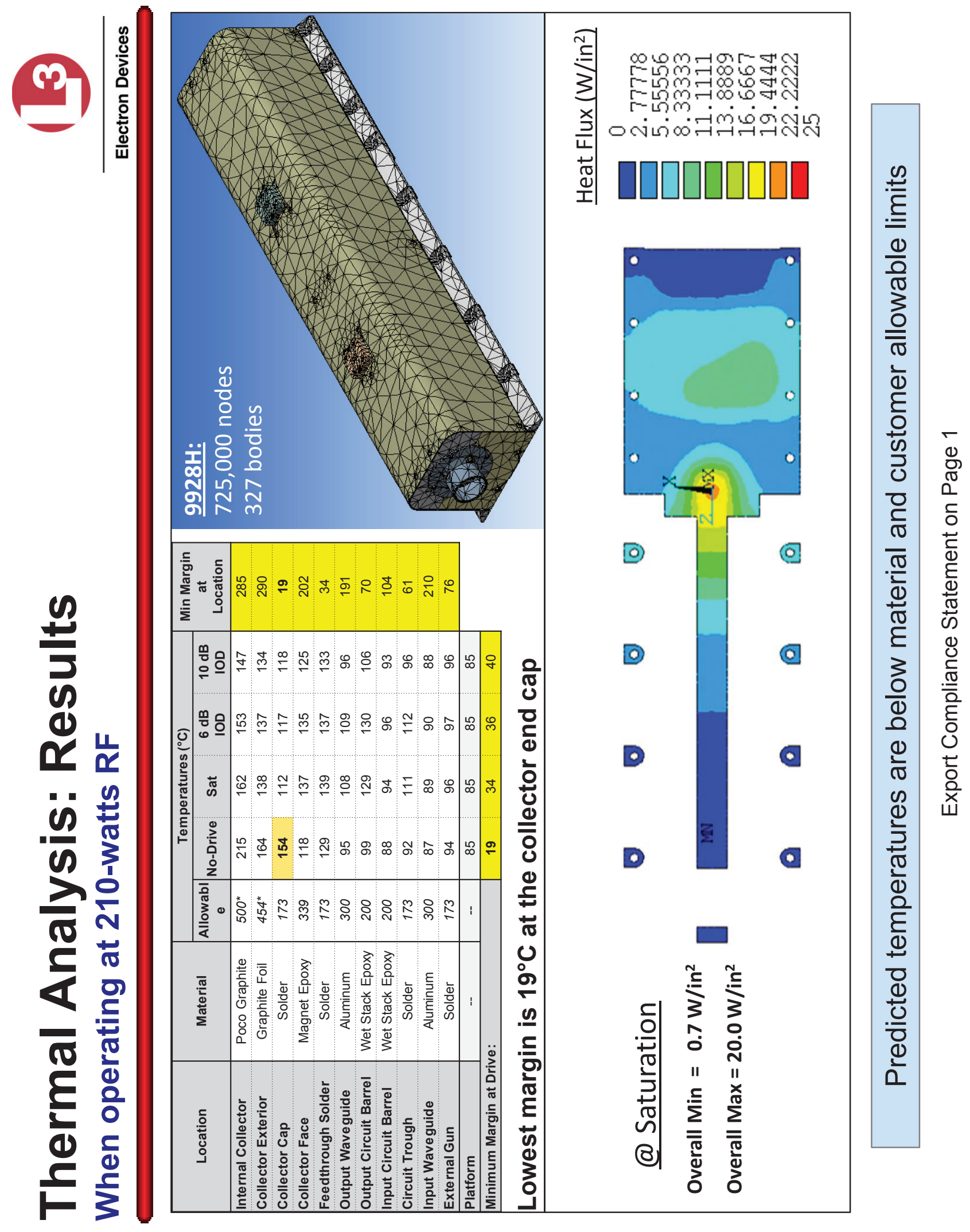




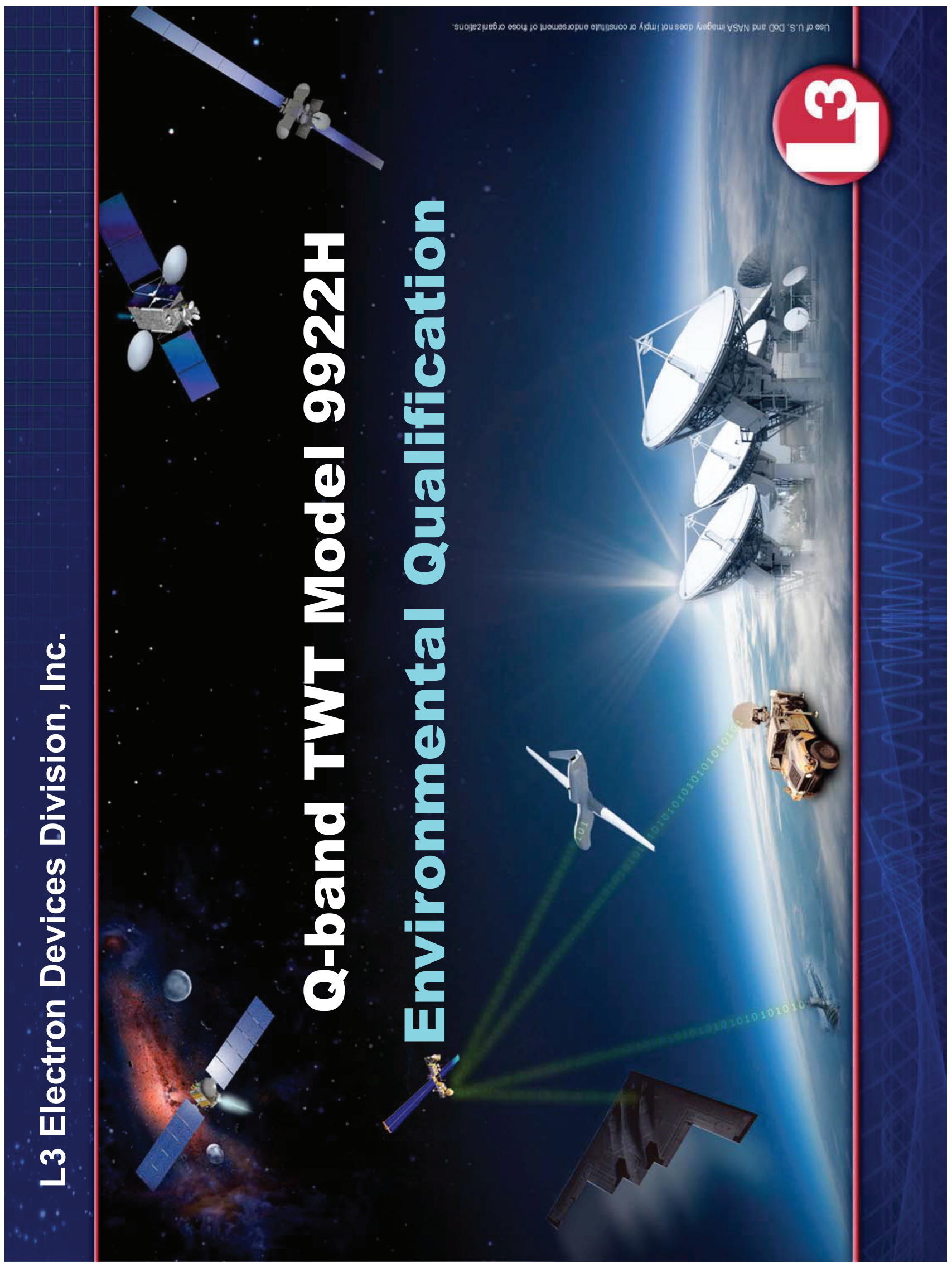

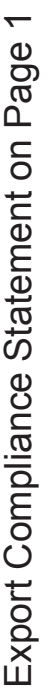




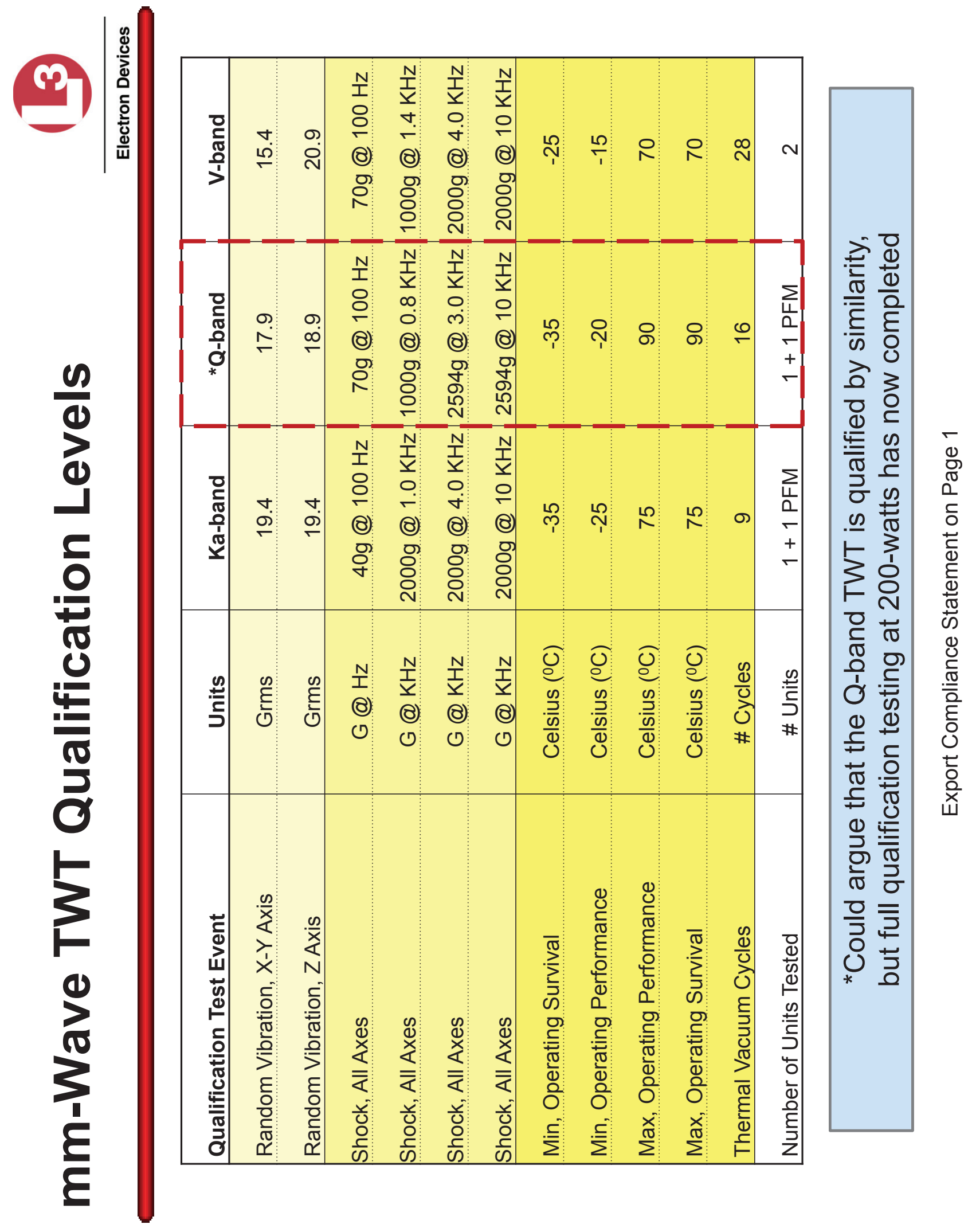



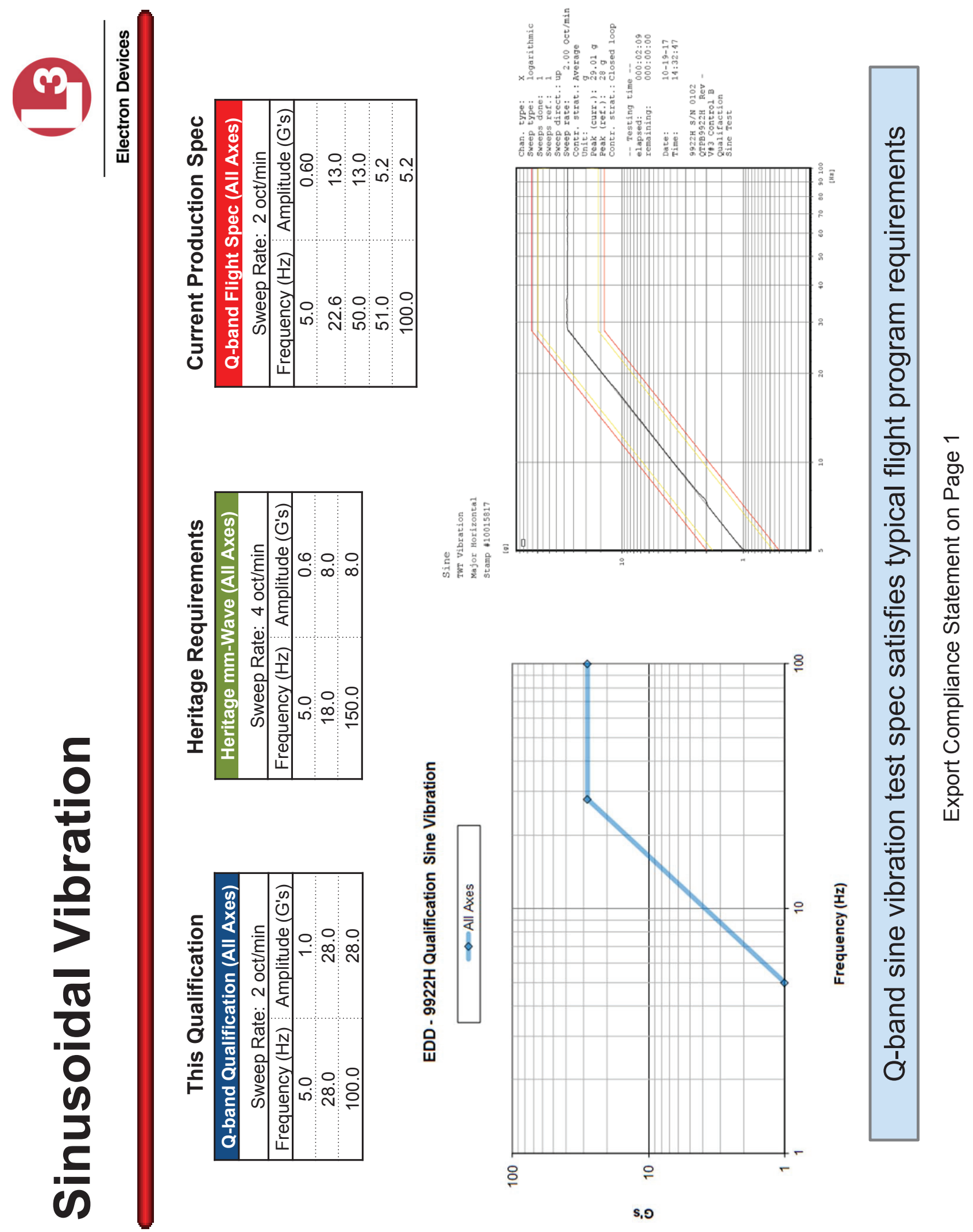

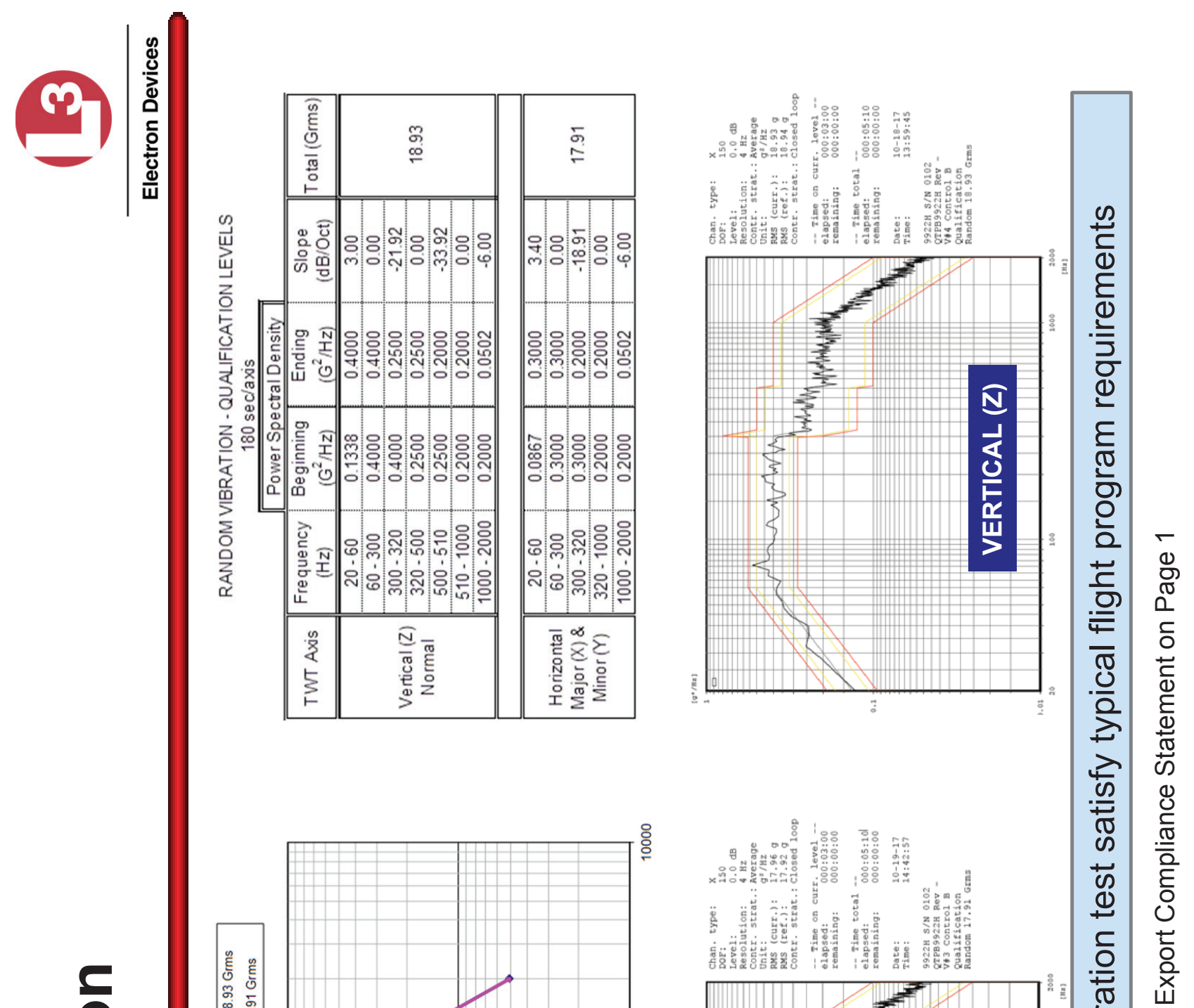


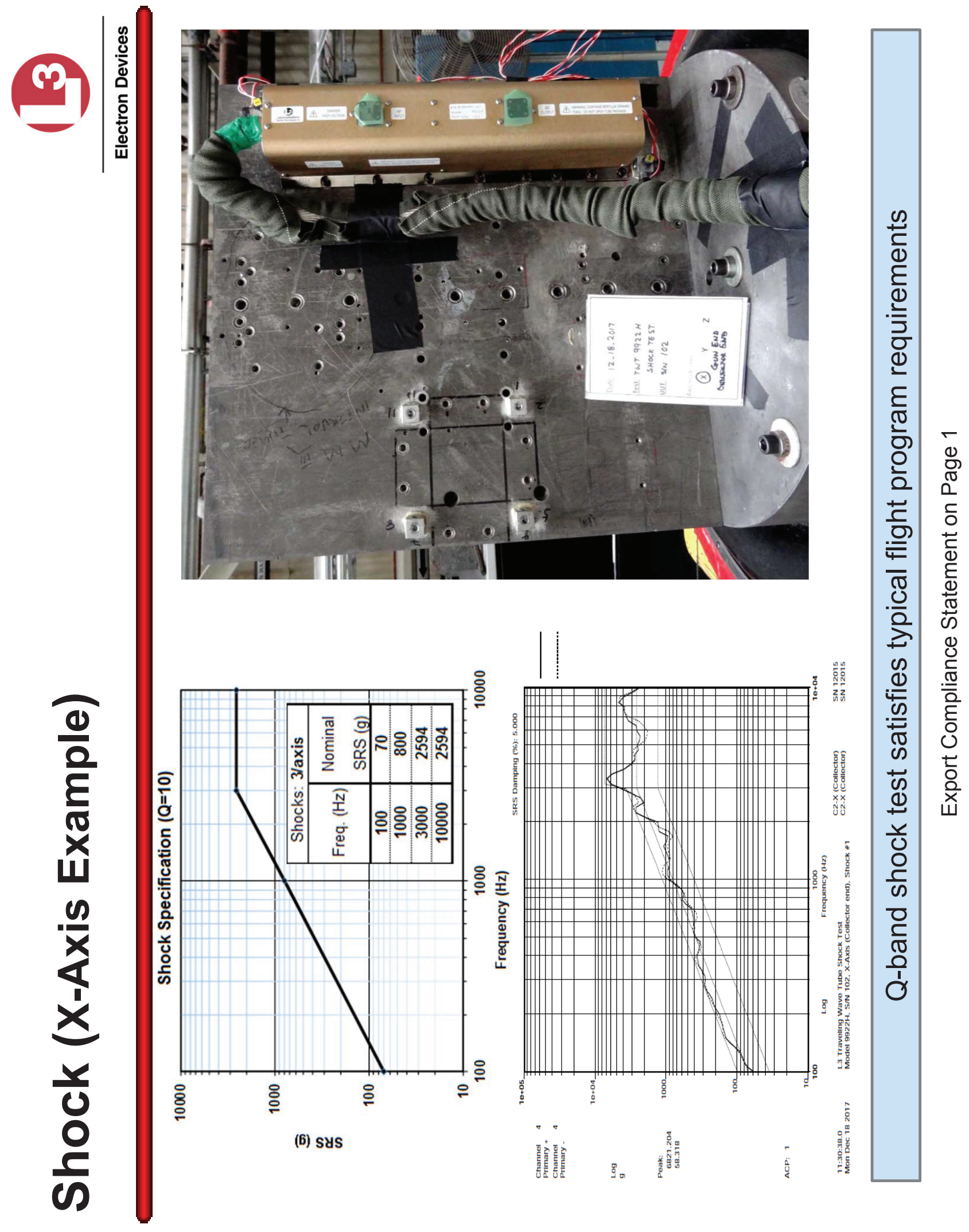




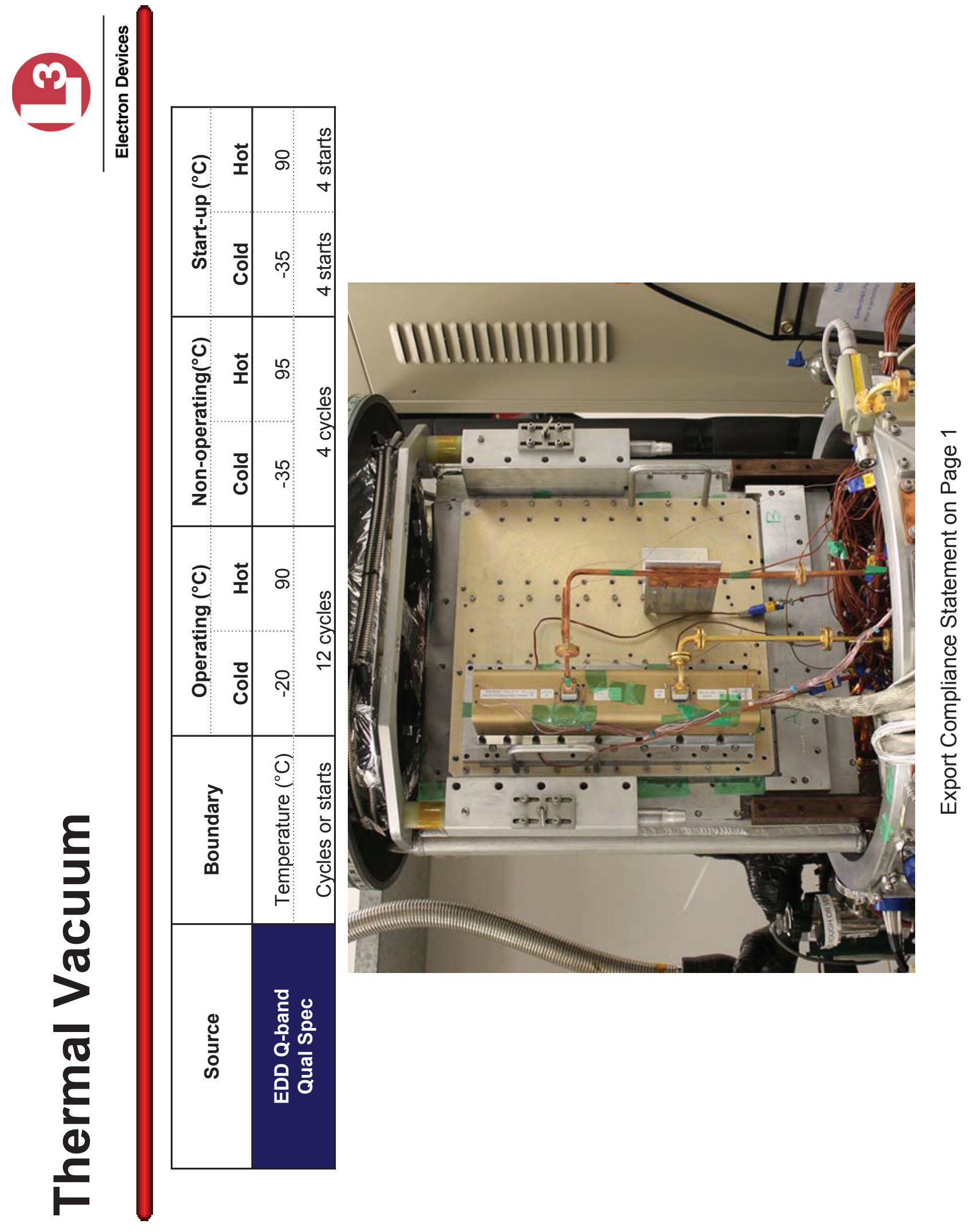




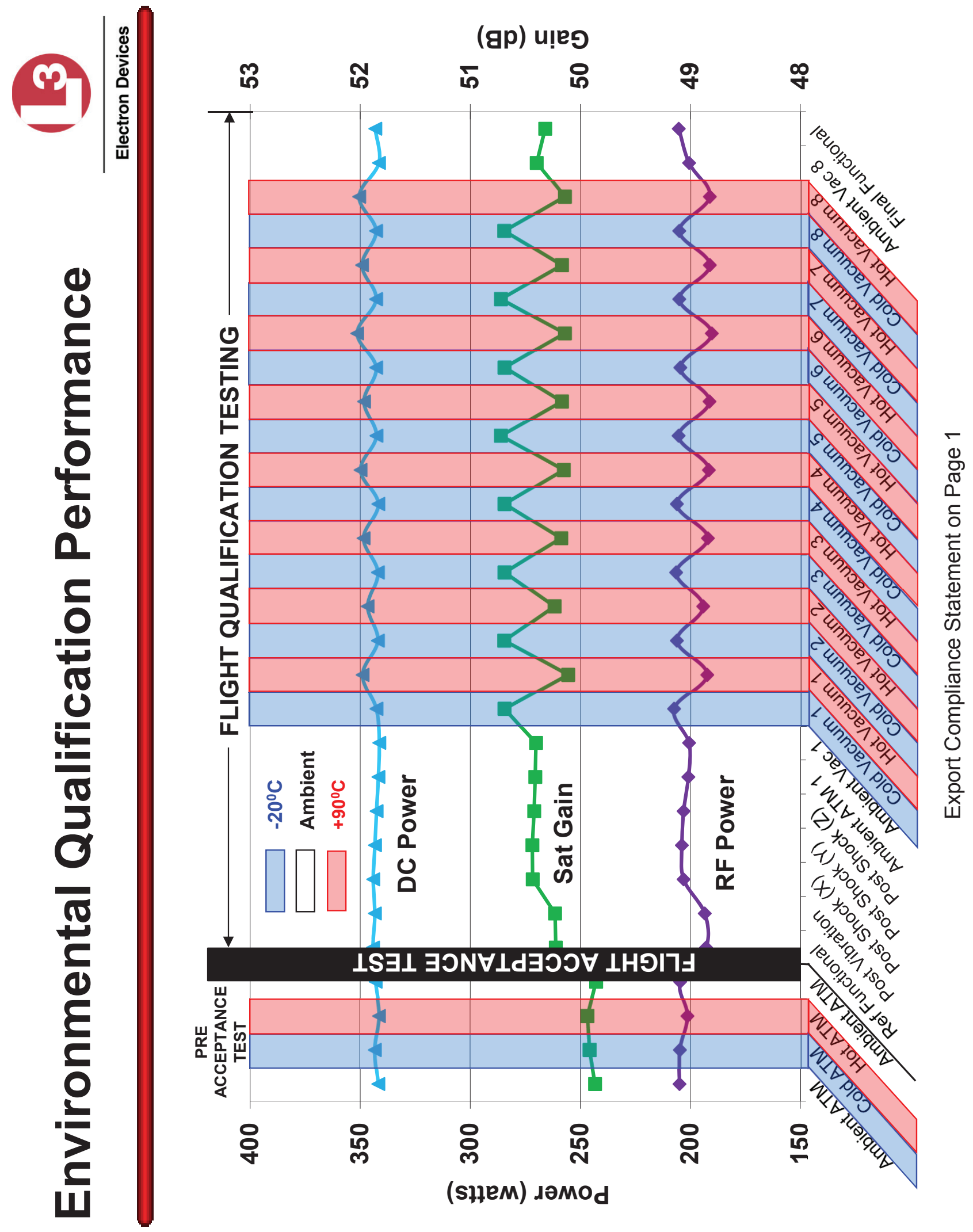




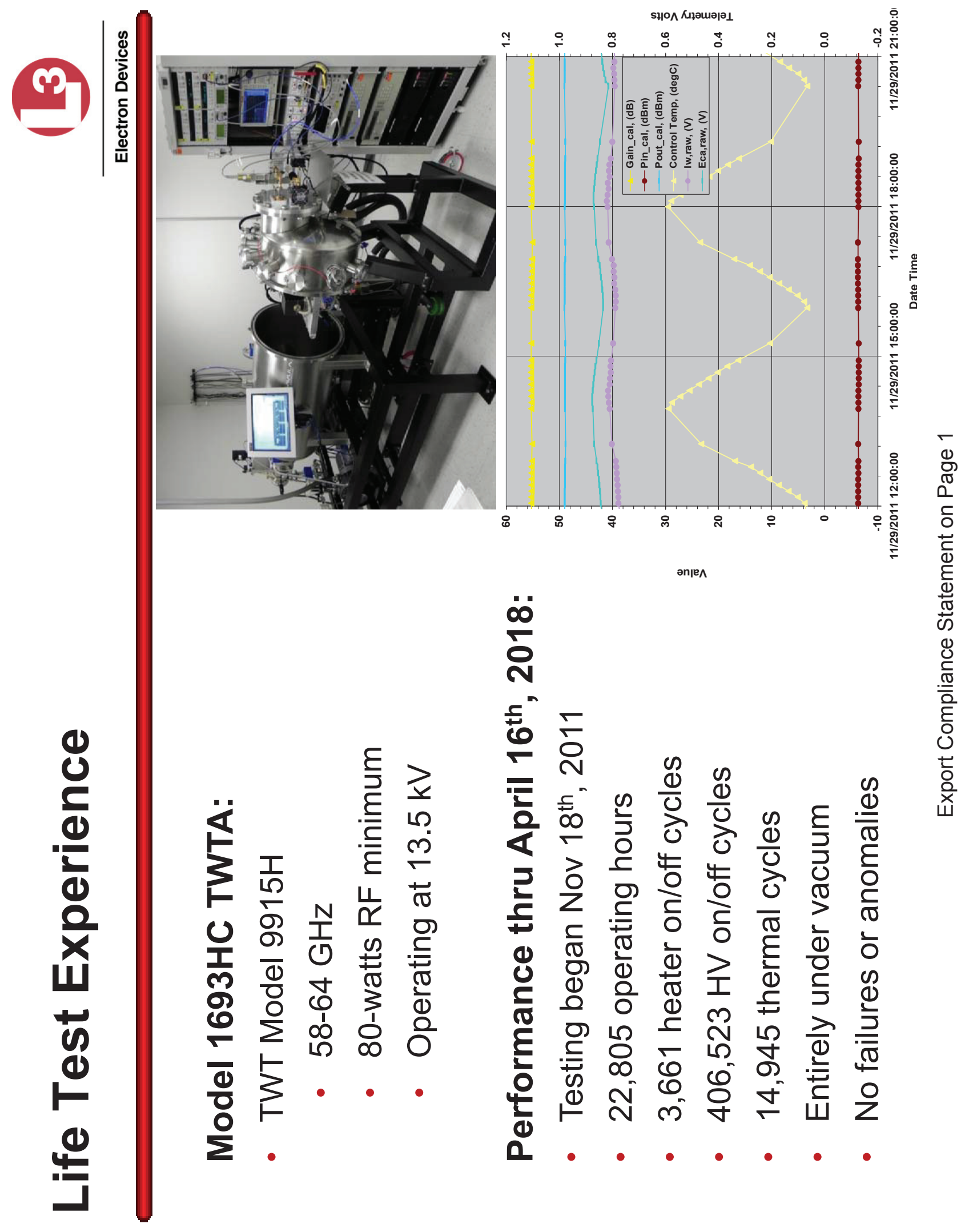




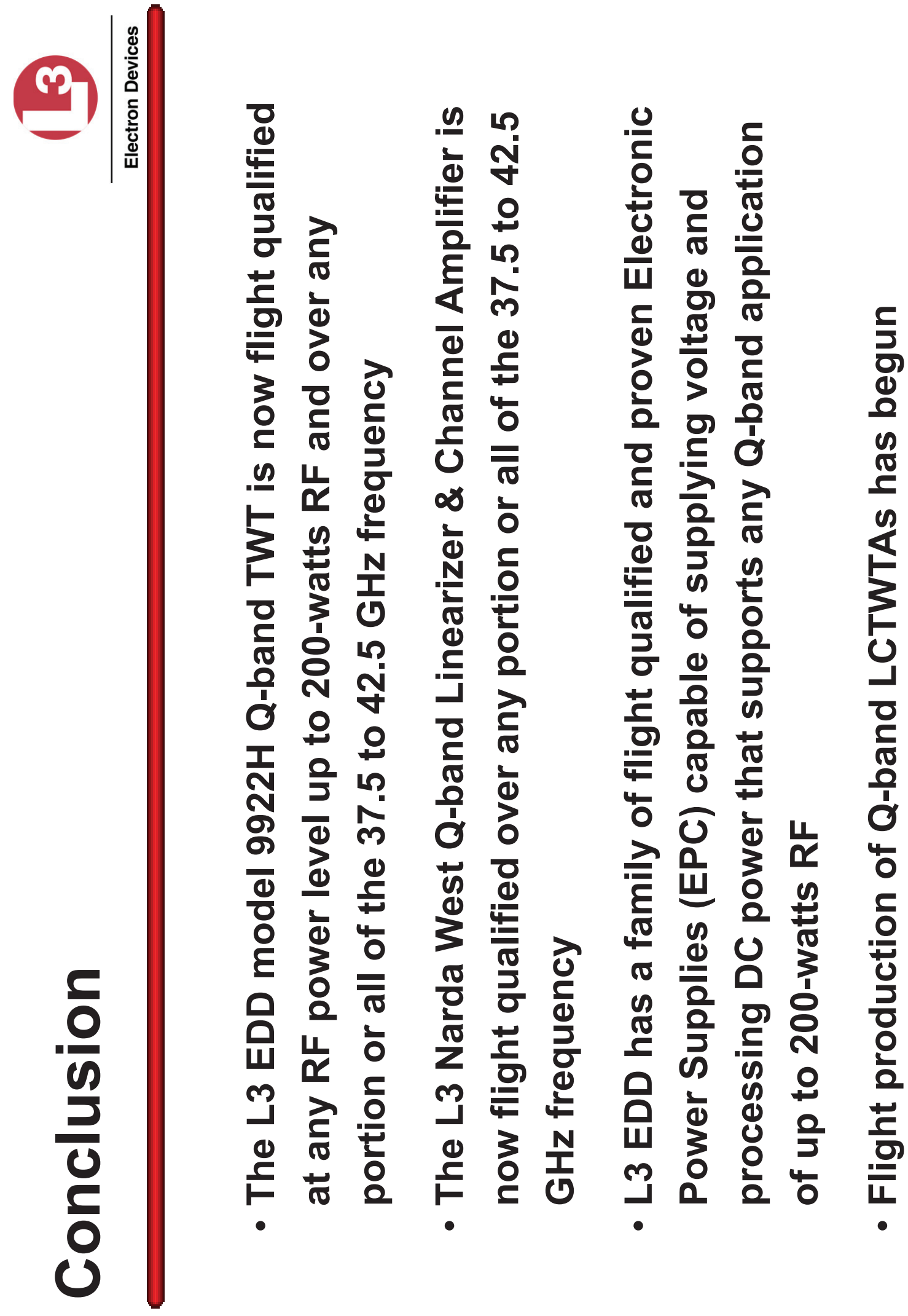




